University of Louisville

ThinkIR: The University of Louisville's Institutional Repository

Electronic Theses and Dissertations

8-2016

\title{
The relationship of reform style professional development and student achievement.
}

Amy Colucci

University of Louisville

Follow this and additional works at: https://ir.library.louisville.edu/etd

Part of the Teacher Education and Professional Development Commons

\section{Recommended Citation}

Colucci, Amy, "The relationship of reform style professional development and student achievement." (2016). Electronic Theses and Dissertations. Paper 2519.

https://doi.org/10.18297/etd/2519

This Doctoral Dissertation is brought to you for free and open access by ThinkIR: The University of Louisville's Institutional Repository. It has been accepted for inclusion in Electronic Theses and Dissertations by an authorized administrator of ThinkIR: The University of Louisville's Institutional Repository. This title appears here courtesy of the author, who has retained all other copyrights. For more information, please contact thinkir@louisville.edu. 


\title{
THE RELATIONSHIP OF REFORM STYLE PROFESSIONAL DEVELOPMENT AND STUDENT ACHIEVMENT
}

\section{By}

\author{
Amy Colucci \\ B.S., Ball State University, 2000 \\ M.Ed., Indiana Wesleyan University, 2005
}

\begin{abstract}
A Dissertation
Submitted to the Faculty of the College of Education and Human Development of the University of Louisville In Partial Fulfillment of the Requirements

For the Degree of
\end{abstract}

\author{
Doctor of Education in \\ Education Leadership and Organizational Development
}
Department of Educational Leadership, Evaluation, and Organizational Development University of Louisville
Louisville, Kentucky

August 2016 

THE RELATIONSHIP OF REFORM STYLE PROFESSIONAL DEVELOPMENT AND STUDENT ACHIEVMENT

\author{
By \\ Amy Colucci \\ B.S., Ball State University, 2000 \\ M.Ed., Indiana Wesleyan University, 2005 \\ A Dissertation Approved on
}

July 12, 2016

by the following Dissertation Committee:

Dissertation Director
Jason C. Immekus

William Ingle

Marco Muñoz

John Ansman 


\section{DEDICATION}

This dissertation is dedicated to my wonderful husband Dan, our two amazing

children, Alex and Emily, and my parents, Bill and Judy. Thank you for believing in me and providing support throughout this entire process. I am very blessed and your support has made this possible. 


\section{ACKNOWLEDGMENTS}

I would like to thank my dissertation chair, Dr. Immekus for your mentorship and guidance through this process. You challenged me through my course work to be a better writer and I am grateful for the opportunity to be a better version of myself. Your attention to detail and strategic thinking has been instrumental in my learning process and I am grateful for your guidance. I would also like to thank Dr. Ingle who helped shape my entire paper through coursework and providing clarity in those moments I wasn't sure any of this made sense. Thank you Dr. Ingle, I will always value your calm and logical nature.

Dr. Munoz, thank you for serving on my committee in light of your heavy workload and changing jobs. It means so much to me as I have always respected the work you do with JCPS. I don't know if I have ever been as happy during this process as I was when you confirmed the statistical significance of my study and I will always appreciate how you mirrored my excitement. Dr. Ansman, thank you for taking the time out of your busy schedule to serve on my committee. You have been the voice of reason and support letting me know there is a light at the end of the tunnel and some things are just part of the process. I appreciate your dedication to my paper and your support through this process. 
Thank you Alex and Emily, you keep me going and I am so thankful for you. Not everyone gets to be the mommy to a turkey and a raccoon. I love you more than you can ever imagine and I am so incredibly proud of both of you. I know these past three years were not easy for you, but you hung in there and supported me every time I needed to do "homework." My hope for you is to know you can do anything you set your mind to with hard work and determination.

To Dan, thank you for being my support system through this process. When the orientation meeting advised us to say goodbye to our spouses for the next three years, they weren't kidding. You have helped manage the kid's schedules when I attended class and offered support when I had to lock myself in a room to write all weekend. This degree is for our whole family, we earned it together, and I love you. :)

To Judy and Bill, thank you for always supporting my education. I didn't think I would still be in school at this point in my life, but the path is always changing. Thank you for your endless love and support, I love you. This process wouldn't be possible with out the support of my entire family, even when I am impressed my brother Bill can answer a statistics questions without even seeing the problem. I appreciate the welcome distraction of spending time with you all and am thankful for your words of encouragement or understanding when I had to do homework when we were together. Thank you for everything, I am lucky to have you all.

To my classmates and colleagues, thank you for your words of encouragement, random texts, emails, and pep talks through this process. This is a very isolating endeavor and I appreciate your forgiveness when I didn't return a text right away, or couldn't make an event because of school. Kara and Natalie, our weekly meetings are what kept me 
going through classes, thank you for taking the time out of your already busy schedules to make this experience fun. I will be eternally grateful to you both. 


\title{
ABSTRACT \\ THE RELATIONSHIP OF REFORM STYLE PROFESSIONAL DEVELOPMENT AND STUDENT ACHIEVMENT
}

\author{
Amy Colucci
}

July 12,2016

The adoption of the Common Core State Standards (CCSS) in mathematics represents a challenge for public educators due to the broad scope of required instructional change. This quantitative study investigated the implementation of a reform style professional development program in Jefferson County Public Schools (JCPS), a large urban school district in Kentucky. The research questions included in the study are: (a) Is reform style professional development positively associated with students' mathematics achievement? and (b) What are teacher's perceptions of reform style professional development's effectiveness on their instructional practices and student achievement? Student achievement was measured using norm-referenced mathematics scores from the Kentucky Performance Rating for Educational Progress (K-PREP), the state assessment for Kentucky. A hierarchical linear multiple regression model was used, controlling for student variables in block 1 , prior year test scores in block 2 , and teacher participating in reform style professional development in block 3 . 
Findings suggest there is a positive and significant difference in student mathematics achievement in classrooms where teachers partially participate or fully participate in reform style professional development. This study may benefit educational leaders by providing data surrounding an effective professional development model, which has a positive relationship with student achievement. 


\section{TABLE OF CONTENTS}

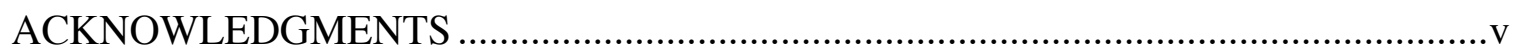

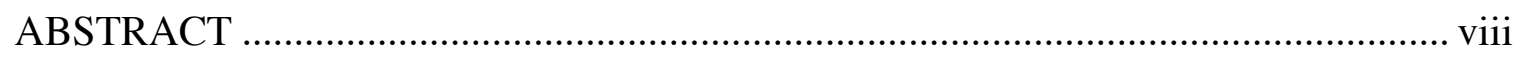

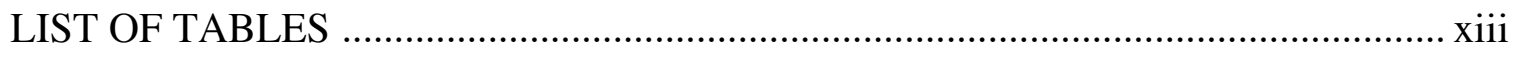

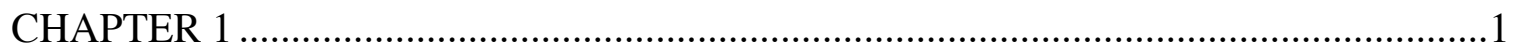

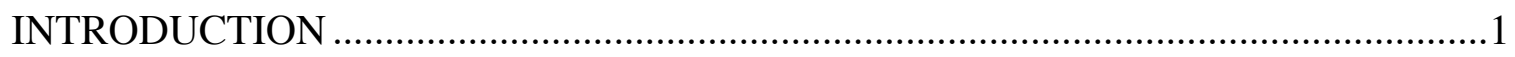

Background of Study ..................................................................................

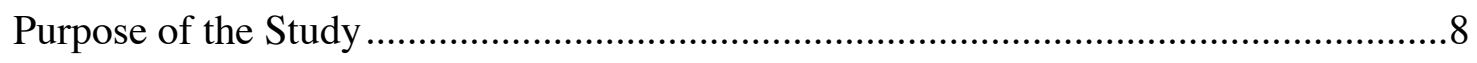

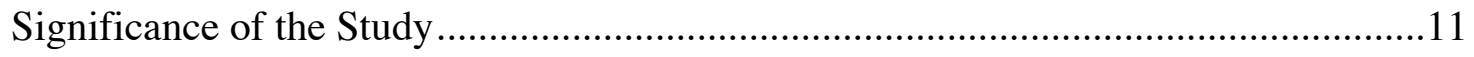

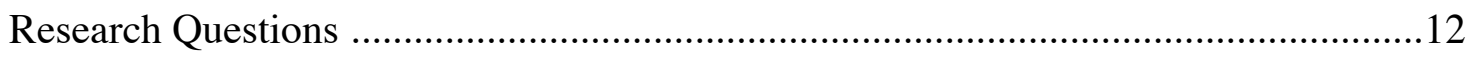

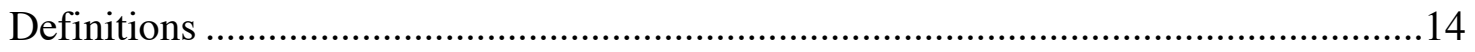

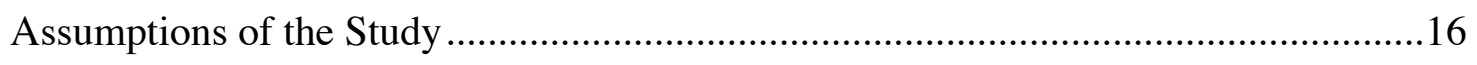

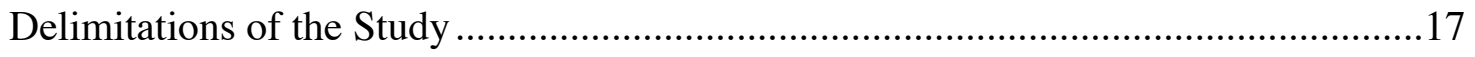

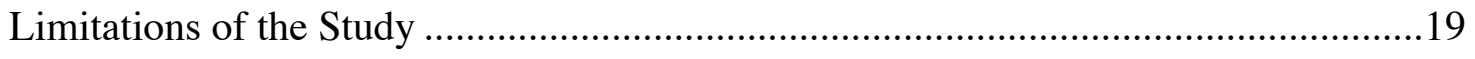

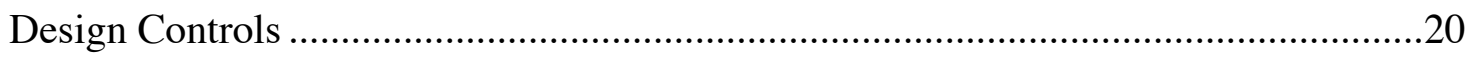

Organization of Subsequent Chapters …....................................................... 21

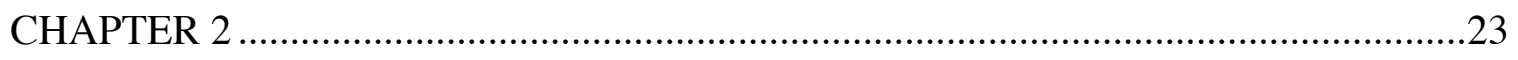

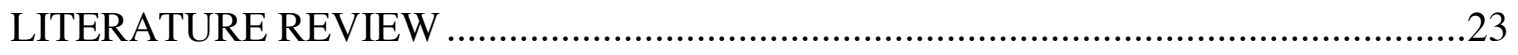




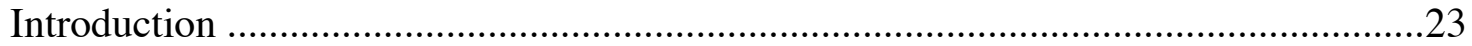

The Common Core State Standards: World-Class Standards Movement .....................24

Origins of Common Core State Standards ………...................................................32

Common Core State Standards Adoption...................................................................

The Role of Professional Development in Advancing Educational Reform ..................40

Summary of Literature Review Findings ……………........................................48

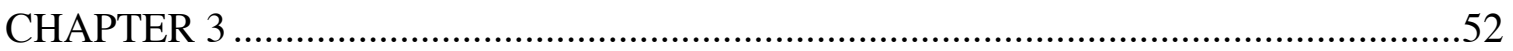

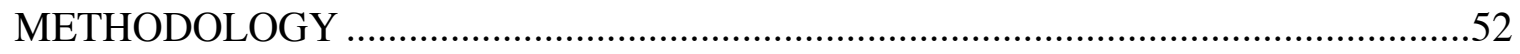

Research Questions ........................................................................................52

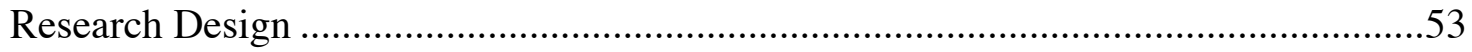

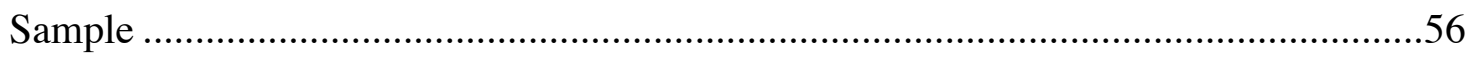

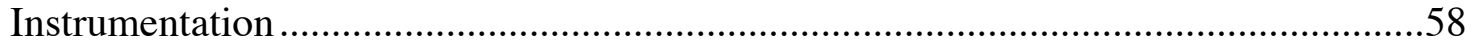

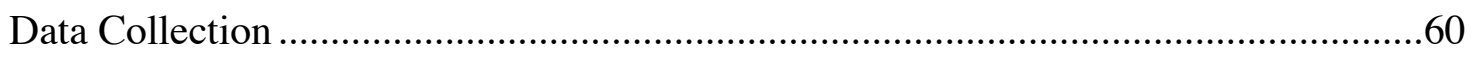

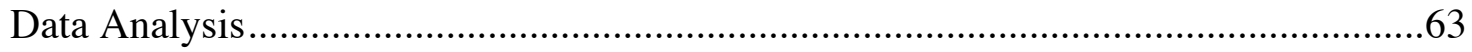

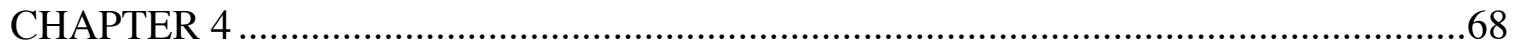

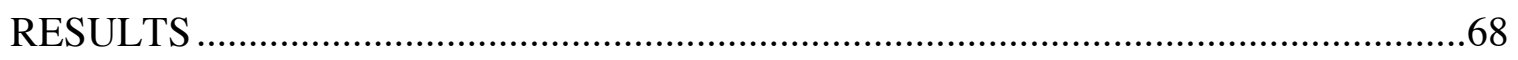

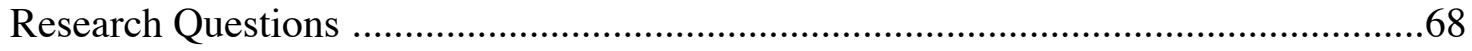

Participants and Descriptive Statistics.................................................................69

Null and Alternate Hypotheses ...............................................................................70

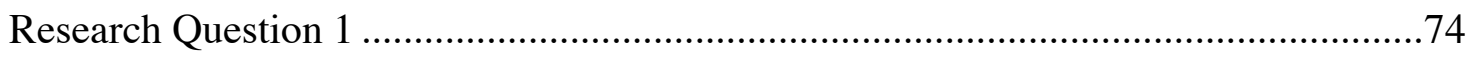

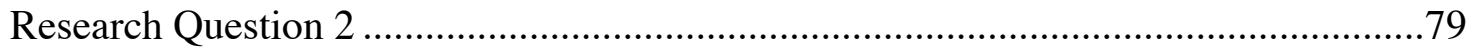


CHAPTER 5

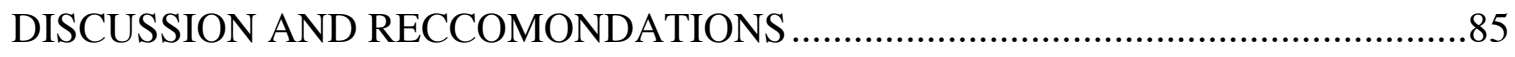

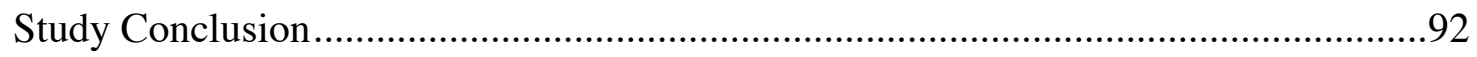

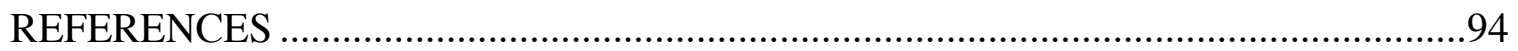

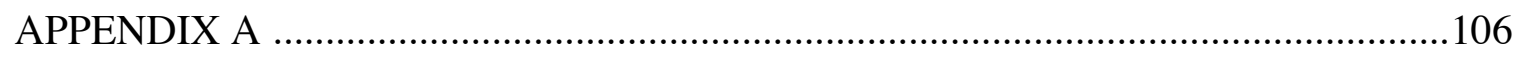

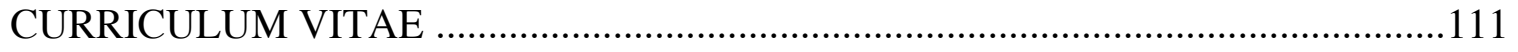




\section{LIST OF TABLES}

Table 1 Measurement of Variables..............................................66

Table 2 Student Demographic Variables........................................ 70

Table 3 Descriptive Statistics..............................................

Table 4 Descriptive Statistics for Teacher Groups..............................74

Table 5 Hierarchical Multiple Linear Regression Results............................78

Table 6 Hierarchical Multiple Linear Regression Model Summary....................79

Table 7 Teacher Survey Frequencies............................................. 82 


\section{CHAPTER 1}

\section{INTRODUCTION}

\section{Background of Study}

Throughout the past 200 years, educational reform in the United States (U.S.) has brought about a host of changes in attempts to increase academic achievement (Wallender, 2014). Most recently, the Common Core State Standards (CCSS) initiative was introduced to raise academic achievement throughout the United States. The CCSS movement has the potential to be one of the most significant policy shifts in American education in more than a century (McDonnell \& Weatherford, 2013). The CCSS represent the best effort thus far to transform today's patchwork quilt of state standards into a more aligned set of standards containing strong consistent expectations for what all students should know and learn (Weingarten, 2010). The CCSS were developed with the goal of meeting the academic requirements necessary for 21 st century students to be successful, while also expecting teachers to provide instruction at a higher academic level in the classroom (Rotman, 2012). This shift to a set of more rigorous nationwide standards has prompted virtually every school district in the United States to undergo some type of reform effort and implement a professional development program for their teachers (Youngs, 2013). Heightened benchmark assessments to measure student achievement and raised curricula expectations are only two of the demands placed on 
teachers who are already tasked with changing their instructional practices to accommodate these new standards (Gewertz, 2013). The continual modification of what schools expect of their teachers regarding mathematics instruction, illustrate the need for ongoing and effective teacher professional development (Conley, 2014).

The goal of the CCSS is to increase math literacy for all students through instructional activities grounded in critical thinking, communication, and collaboration (Common Core State Standards Initiative, 2010). Students demonstrating math literacy are better able to analyze and reason while formulating, solving, and interpreting solutions to problems across a variety of situations (Program for International Student Assessment, 2012). Mathematical capability, essential in the $21^{\text {st }}$ century workplace, is a key indicator of productivity (Vigdor, 2013). As students face "unprecedented challenges and heightened competition" in the global, knowledge-based job market, accelerating college realization is more than educational policy, it is an urgent national pursuit (U.S. Department of Education, 2013a, p. 1). With the adoption of the CCSS in 43 states, educators are committed to providing a free education that produces students who are equipped to meet the complex challenges of the $21^{\text {st }}$ century (Standards in Your State, n.d.).

The United States struggles with mathematics performance among elementary students, currently placing $27^{\text {th }}$ on international rankings (Program for International Student Assessment, 2012). Despite numerous education reforms, including George W. Bush's No Child Left Behind Act of 2001, mathematics performance continues to fall short in the United States, especially among minority subgroups and students of poverty (Confer \& Ramirez, 2012). An analysis of countries that routinely outperform the United 
States, reveal mathematics education built upon a foundation of common standards, as opposed to multiple, disjointed standards encompassed by the United States prior to the CCSS, is essential to increasing achievement (McCarthy, 2012). According to the 2015 data from National Assessment of Educational Progress (NAEP), 35\% of the U.S. class of 2015 reached or exceed the proficiency level in math. This percentage places the United States at the 27th rank among the 34 Organizations for Economic Cooperation and Development (OECD) countries. The percentage of students who are math proficient is nearly twice as large in Korea (65\%), Japan (59\%), and Switzerland (57\%). Other countries with performances that clearly outrank the United States include Finland (52\%), Canada (51\%), Germany (50\%), Australia (45\%), France (42\%), and the United Kingdom (41\%). Changes must be made to increase mathematics achievement in the United States, over the last thirty years mathematics achievement has not increased significantly, despite multiple standards based reform movements.

Results from the 2012 NAEP long-term trend assessment indicates there was not significant improvement in elementary student's math knowledge and skills at the elementary level from 1973 to 2012. Additionally there was not significant change for the same age groups, in a smaller time frame, from 2008 to 2012 (NAEP, 2012). The average score for nine year-olds was 25 points higher in 2012 than in 1973 , a climb from 219 to 244. Thirteen-year-olds scored higher in 2012 than in all the previous assessment years, with a 19-point gain from 1973 and a four-point gain from 2008. The average score in 2012 for 17-year-olds was not significantly different from the score in 1973 . The 40 -year time span only provides a gain of only two points, from a score of 304 in 1973 to 306 in 
2012. Stagnant scores prevail in the United States, even in the face of numerous educational reform movements.

In an effort to raise student achievement, Kentucky $(\mathrm{KY})$ was the first state in the nation to adopt the CCSS and revamp the entire criterion-referenced portion of the Kentucky Performance Rating for Educational Progress (K-PREP) for mathematics. This new assessment was created around the new CCSS and aligned closely with the NAEP assessment (Innes, 2012). Kentucky appears to be right on target, in 2011, 39\% of Kentucky fourth graders were Proficient or More on the NAEP, and 39.6\% of Kentucky fourth graders were ranked Proficient or More in K-PREP math in 2012. With less than $40 \%$ of their fourth grade students, state wide, scoring Proficient or More, Kentucky schools need to continue to strengthen their mathematic education. Based on these assessments scores, Kentucky has been proactive seeking opportunities to better improve student learning in their state by taking advantage of federal programs.

The Obama administration's Race to the Top (RTTT) competitive grant program has been heralded for revolutionizing the federal role in education and transforming state school reform efforts (McGuinn, 2011). RTTT is fundamentally about two things: creating political cover for state education reformers to innovate, and helping states construct the administrative capacity to implement these innovations effectively. This initiative required school districts to incorporate standards-based reforms to drive improvement, tying teacher and principal evaluations to evidence that educators are helping students learn (Manna \& Ryan, 2011). RTTT expects districts to increase teacher effectiveness and turn around underperforming schools using common standards, thereby eradicating the achievement gap (Manna \& Ryan, 2011). To achieve the president's goal 
of restoring the United States as the world's leader in college graduates by 2020, educators must fundamentally transform their mathematics instructional practices and develop a deep understanding of the new CCSS (U.S. Department of Education, 2013b). Mathematics teachers, who previously focused on delivering the curriculum, must now focus on practices that guide and enable learning so students understand why the answer they end up with is correct or incorrect. A change in teacher focus for instruction will require effective professional development (Youngs, 2013).

Prior to RTTT, the No Child Left Behind Act of 2001 stated, "high-quality professional development is considered an essential strategy to turning around failing schools" (NCLB; No Child Left Behind, 2003, p. 49). High-quality professional development programs incorporate various strategies to support the learning of all teachers. Teacher professional development programs have the long-term goal of implementing a solid curriculum and teaching practices that research indicates will support student success. School districts often struggle to determine which professional development style is most successful in ensuring increased student achievement. The traditional method of providing professional development (e.g., hiring consultants, sitting auditorium-style, lecture, group discussion, etc.) are no longer sufficient in providing transformative changes to teacher practices that result in increased student achievement (Stein, Smith, \& Silver, 1999). School districts must provide high quality professional development, focused around quality standards and instructional practices to increase student achievement.

Professional development is delivered through a variety of methods in school districts. Typically, this occurs through study groups, peer coaching, induction training 
for new teachers, mentoring for beginning teachers, peer observation, networking, conferences, workshops, and institutes. However, as noted in the literature, professional development activities can be classified into two overarching categories; reform style and traditional style (Garet, Porter, Desimone, Birman, \& Yoon, 2001). The reform style of professional development is a focused set of activities designed to coach and provide feedback that ensures classroom implementation of an innovation. Characteristics of reform style include being sustainable, ongoing, and embedded in classroom practice. Research suggests this type of professional development is more effective because it makes connections with classroom teaching and is usually sustained over a longer period of time (Garet et al., 2001). When professional development occurs consistently, teachers are more likely to discuss concepts, issues, share materials, and develop common student needs (Garet et al., 2001). The more common type of professional development is traditional style, which generally consists of a fragmented one-time approach, with a leader or expert conducting the training (i.e. workshops, institutes, courses, conferences). This form usually consists of a structured approach to professional development that occurs outside the teacher's classroom, often off district property, and frequently in another city or state (Garet et al., 2001).

There are many characteristics of effective professional development that have evolved as education has progressed. Professional development is more effective when closely aligned to district or school initiatives, grounded in research, encompasses curriculum content and design, demonstrates respect for adult learners, draws on the expertise of teachers, provides sufficient time for follow-up support, and viewed as an integral part of teachers' work (Corcoran, 1995). Significant change in teachers' attitudes 
and beliefs occurs primarily after they gain evidence of improvements in student learning. These improvements typically result from changes teachers have made in their classroom practices as a result of the professional development they attended, a new instructional approach, the use of new materials or curricula, or simply a modification in teaching procedures (Guskey, 2002). Twenty-five years ago, a groundbreaking study was published demonstrating that teacher professional development could improve student achievement. Carpenter, Fennema, Peterson, Chiang, and Loef (1989) randomly assigned 40 first-grade teachers to two groups. One group received a brief, four-hour professional development program. The other group received an extensive 80-hour program focusing on instructional practices. Twelve students, six girls and six boys, were randomly selected from each class to provide data on student outcomes. Students with special learning needs were omitted from the random selection. Data collected at the student level included a standardized mathematics achievement test, Iowa Test of Basic Skills (ITBS), and an interview to assess students' problem solving strategies. The students of the teachers who received instructional practices based professional development outperformed the students of the other teachers on both student achievement measures that were examined. Encouraged by findings like this, policy makers have sought to make the professional development that teachers participate in more effective at raising student achievement. For instance, the professional development supported under NCLB is expected to improve the quality of teaching and increase student achievement, and encourages school districts to adopt programs and practices that are supported by scientifically-based research (Birman, LeFloch, Lekotka, Ludwig, Taylor, \& Walters, 
2007). Research-based professional development, provided consistently, and focusing on instructional practices, can increase student achievement.

When researching the characteristics that make teacher professional development effective, Kennedy's (1998) literature review focusing on mathematics professional development programs was perhaps the first widely circulated review to address this topic. In addition to showing that professional development could be effective, Kennedy's (1998) review sought to identify the features of effective professional development programs. To do so, Kennedy categorized studies according to the professional development being studied. She found that the relevance of the content of the professional development was important. She concluded programs whose content focused mainly on teachers' behaviors demonstrated smaller influences on student learning than those programs whose content focused on teacher knowledge of the subject, of the curriculum, and how students learn (Kennedy, 1998). Kennedy's literature review suggested an important role for content emphasis in high-quality and effective professional development. Her work prompted others to test the same hypothesis in subsequent studies that would reach a similar conclusion. These studies concluded teachers need effective professional development in order to increase student achievement (Desimone, Porter, Garet, Yoon, \& Birman, 2002; Garet et al., 2001; Yoon, Garet, Birman \& Jacobson, 2006).

In an effort to meet the criteria of RTTT, provide effective professional development, and increase student achievement, Jefferson County Public Schools (JCPS) invited two teachers from each of the district's 90 elementary schools to participate in a CCSS professional development opportunity. This professional development focused on 
the reform style criteria. A series of four sessions were provided. Each focused on CCSS and content specific pedagogy, which centered on developing conceptual mathematics understanding for students. The district identified a curricular alignment problem within $60 \%$ of their elementary schools (JCPS at a Glance, n.d.), meaning the teaching methods present in schools did not align with the CCSS mathematical practices for instruction (National Governors Association Center for Best Practices \& Council of Chief State School Officers, 2010; U.S. Department of Education, 2013b). This reform style professional development opportunity strove to close the learning gap for teachers when teaching the CCSS.

The present study sought to examine if reform style professional development, focused specifically on elementary math instruction, was associated with increased student achievement. JCPS, the urban school district that serves as the context for this study, spent an estimated $\$ 657,131$ on professional development during the 2014-2015 school year. This does not include teacher opportunity costs for the days each of them were out of the classroom and required a substitute (JCPS Transparency Site, 2015). The daily estimated rate for a substitute teacher is $\$ 205$. With this amount of money spent annually on professional development it would be advantageous for the school district to understand if the professional development opportunities provided accomplish the goal of increasing student achievement, or if the money could be spent in other areas.

\section{Purpose of the Study}

The purpose of professional development is facilitating teacher change to improve student outcomes by altering their instructional strategies to increase skill level and ability so that they are able to transfer what they have learned to positively influence 
student achievement in their classroom (Guskey, 2000). The purpose of this study was to examine the relationship of reform style, CCSS focused, instructional strategy based, professional development and student achievement in JCPS, a large urban school district in Kentucky. It was the researcher's hypothesis that by adopting the CCSS and providing teachers targeted, high quality professional development, there would be a significant positive influence on student achievement, and a lasting influence on teacher's instructional practices in the classroom. This would provide sound evidence to continue to provide reform style professional development, considering the additional cost associated with an extended and continuous professional development implementation.

The JCPS strategic plan outlines a commitment to closing the achievement gap in mathematics through consistent and effective teaching practices reinforced through research-based professional development. Educational leaders within the organization embrace the notion that all children, regardless of race, socio-economic status, or limited English proficiency, can and will succeed in math. The district supports a performancebased approach in which students are expected to inductively create meaning from math concepts through collaborative tasks, real-life application, active participation, and student-dominated discussions. Student learning is not measured based on the correct answer, it is measured by evaluating the steps the student used to get to the correct answer. Students are actively participating in math reasoning and problem-solving methodology aligning with the mathematical practices introduced in the CCSS. Teachers assume a more facilitative role in the classroom, using questioning techniques to guide students to formulate responses through critical thinking and analysis, while requiring them to provide their answers through evidence-based rich discussion. This presented 
quite the challenge for JCPS curriculum leaders attempting to prepare the district's 5,200 mathematics teachers for a performance-based approach to mathematics instruction.

JCPS tasked District Curriculum Coordinators to develop and implement highquality professional development designed to address the evolving needs of the student population, while fostering lasting changes in the instructional practices of their teachers to align with the CCSS. In order to train teachers to implement cohesive strategies for improving conceptual number sense in grades kindergarten through fifth, a district-wide math professional development initiative was developed. This professional development model was based in research and included multiple departments during the planning and deliver process. Seven district employees were involved in the implementation of this professional development program. This group consisted of, one math specialist, two math resource teachers, two instructional technology resource teachers, two special education resource teachers, one social studies resource teacher, one music resource teacher, and one art resource teacher. During the 2014-2015 school year, this group collaborated to develop and conduct four cycles of CCSS focused, reform style professional development.

Schools were invited to send two teachers, but could send additional teachers if they could cover the cost of substitute teachers. Participating teachers were invited to attend one six-hour day of professional development during each of the four grading periods. Each cycle contained six identical sessions, one for each sub group of elementary schools organized by geographic location. Classroom teachers were invited to attend four, six-hour sessions, scheduled to include other schools geographically close to them to encourage collaboration between schools. This research-based professional 
development opportunity was offered to all 90 elementary schools to focus on CCSS math instruction. The objective of the math professional development was to understand the CCSS and how they spiraled through all six elementary grades, as well as model and discuss specific methodology teachers were encouraged to use in their classrooms. These strategies included student discourse, formative assessment, formative assessment lessons, student focused question creation, word problem schema, and encouraging students to solve problems and develop strategies. These focus strategies were data driven using prior year state assessment data, along with current, district-created, mathematics diagnostic assessments, to identify areas of growth for students in JCPS.

\section{Significance of the Study}

Since the 1990s, educational reform efforts have focused on school structure, design, and instructional delivery changes as means for increasing student achievement (Starman, Larson, Proffitt, Guskey, \& Ma, 2014). These three categories reflect the primary ways in which states, including Kentucky, have sought to change the provision of education. States shifted their focus from school inputs, such as per-student expenditures on instructional materials, to student outcomes, such as the percentage of students attaining a score of proficient on a statewide assessment. Kentucky believed by changing the structure, design and instructional delivery of their schools, they could focus on the outputs like student achievement. For example, school districts implemented Early College High Schools, Career Academies, Freshman Academies, adopted the CCSS, and chosen to employ external providers to deliver professional development to influence and alter instructional methods (Tyack \& Cuban, 1995). While current education reform in Kentucky focus on increasing student achievement via rigorous standards, the addition of 
effective professional development could allow Kentucky to meet the academic demands of today's students.

The findings of this study will provide empirical evidence regarding the relationship between district-wide, reform style, professional development and its effect on student mathematics achievement at the elementary level. Following the reform style professional development, this study collected and analyzed survey data on teacher attitudes and perceptions of the professional development and its perceived relationship with student achievement. Student achievement was measured by the Kentucky Performance Rating (Kentucky Department of Education, 2014b) assessment, a state mandated norm-referenced mathematics assessment.

\section{Research Questions}

This study seeks to answer the following research questions:

Research Question 1: Is reform style professional development positively associated with students' mathematics achievement?

Research Question 2: What are teacher's perceptions of reform style professional development's effectiveness on their instructional practices and student achievement?

A correlational research design was used address Research Question 1, whereas a cross-sectional survey research design was used to examine Research Question 2.

Correlational research involves collecting data in order to determine whether, and to what degree, a relationship exists between two or more quantifiable variables (Gay \& Airasian, 2000). The purpose of a correlational study is to determine relationships between variables or to use these relationships to make predictions. Correlational research never establishes cause-effect links between variables. Correlational research is a 
nonexperimental method since it lacks the manipulation of an independent variable, which is under the control of the researcher, and random assignment of participants is not possible. This means, among other things, that the variables must be observed as they occur naturally. Some quantitative independent variables that cannot be manipulated and might be used in a correlational study are intelligence, aptitude, age, school size, income, GPA, or any personality trait that is operationalized as a quantitative variable (Johnson, 2001). The key characteristic of the independent variables used in correlational studies is that they either cannot be manipulated or they were not manipulated for various reasons (e.g., ethical concerns or a lack of resources). A cross-sectional survey research design was used to address Research Question 2. This design was chosen because of its simplicity and ability to provide information of how participants feel about a particular subject (Yegidis, Weinbach \& Morrison-Rodriguez, 1999). This survey was used to collect perceptions of educators participating in a reform style professional development to determine what if any components of the professional development most influenced their teaching practices the following school year.

In this quantitative research study, the researcher sought to determine if focused reform style professional development would increase students' mathematics achievement. To examine the contributions of reform style professional development on student achievement, this study used data from the norm-referenced part of the K-PREP state assessment (Kentucky Department of Education, 2014b). While researchers may choose to use the criterion-referenced section of the K-PREP assessment, for the purpose of this study, and to compare results nationally, the norm-referenced section was used. The independent variables include: Exceptional Childhood Education (ECE) (e.g. 
students with an Individual Education Plan) eligibility, Limited English Proficiency (LEP) eligibility, free lunch eligibility, reduced lunch eligibility, prior year test scores, and teacher participation in reform style professional development. Teachers must attend two or more of the offered sessions to be included in the study as fully participating, teachers who attended one session are considered partially participating, and teachers who did not attend any sessions are considered not participating. The dependent variable for this study is student achievement mathematics data from the norm-referenced part of the K-PREP assessment. This study planned to use students' K-PREP scores from third grade, 2012-2013, fourth grade, 2013-2014, and fifth grade 2014-2015 as the basis of measure for student achievement to examine whether reform style professional development is related to student achievement.

\section{Definitions}

The following terms are used in the context of this study:

Achievement Gap - The difference in the performance between each subgroup within a participating school or school district and the statewide average performance of the state's highest achieving subgroups in reading/language arts and mathematics, as measured by designated assessments (U.S. Department of Education, 2013b).

College and Career Readiness - The ability to be successful in entry level, credit bearing, academic courses through colleges and universities and in vocational training programs (Rotman, 2012).

Common Core State Standards - Common set of K-12 content standards that define what students must know and be able to do and that are substantially identical across all States in a consortium. A State may supplement the common standards with 
additional standards, provided that the additional standards do not exceed 15 percent of the State's total standards for that content area (U.S. Department of Education, 2013b).

Global Achievement Gap - The discrepancy between the skills students in the United States posses, compared to the set of skills necessary to be successful in the competitive global economy and workplace (Wagner, 2012).

Professional Development - activities that are an integral part of school and local educational agency strategies for providing educators (including teachers, principals, other school leaders) with the knowledge and skills necessary to enable students to succeed in a well-rounded education and to meet the challenging State academic standards (NCLB, 2001).

Mathematics Achievement - Student performance on the K-PREP mathematics assessment, norm-referenced Part A, as reported by individual scaled scores.

Norm-referenced assessment - assessments designed to separate people into groups based on performance. No all students can be above average on a norm-referenced test as they are designed to yield a spread of scores over a normal distribution (Mertens \& McLaughlin, 2004).

RTTT Fund - 4.35 billion dollar competitive grant program implemented under the American Recovery and Reinvestment Act (ARRA) designed to reward and encourage states creating programs and policies fostering innovation and reform, including raising student achievement, closing the achievement gap, and ensuring college and career readiness for all students (U.S. Department of Education, 2013b).

Reform Style Professional Development includes the following components: ongoing and connected to practice, focus on student learning and address the teaching of 
specific curriculum content, align with school improvement priorities and goals, should build strong working relationships among teachers, be based on CCSS, and provide generous amounts of time for collaborative work and various learning activities. In addition, all professional development sessions must include: objectives, actively engaged participants, modeling, practice, and time for planning for implementation (Wei, Darling-Hammond, Andree, Richardson, \& Orphanos, 2009; Garet et al., 2001).

Traditional Style Professional Development typically includes the following characteristics; one-size fits all techniques, little or no follow-up, lack of proper evaluation, lack of program ownership among teachers, and prescriptive ideas from a topdown-decision-making approach (Diaz-Maggioli, 2004).

Transient Students are defined as any student that changes from one school to another for any reason other than an end of the year promotion (Dover, 2004).

\section{Assumptions of the Study}

The assumptions of this study are as follows. Students in the classrooms studied are comparable; they have the same level of academic ability, socio-economic status, and geographical location. The researcher used socioeconomic level, LEP eligibility, ECE eligibility, and prior year test scores as covariates in an attempt to control for pre-existing variations in student populations. This is critical to determine if teacher participation in reform style professional development made a significant difference in student achievement gains. Professional development was implemented as prescribed in the research, and implemented with fidelity. The researcher was present during all professional development presentations and actively participated in the planning and execution of the professional development and can confirm each session was presented 
based on the research-based planning conducted by the committee. This is essential since each of the four grading periods included six identical sessions to accommodate the vast number of regional participates. Any variations in presenters or delivery method between different sessions would provide additional variables to influence student achievement. Maintaining the same presenters, topics and schedules provides consistency between teachers regardless of which individual session they attended.

\section{Delimitations of the Study}

This study was conducted in one large urban school district in the southeastern United States. Participating teachers are limited to fifth grade teachers, in JCPS, during the 2014-2015 academic year. These delimitations make it unlikely the results can be applied to other school districts across the country and is a threat to the external validity

of the study. The goal of this study is to encompass all teachers who participated in the professional development, either fully or partially as compared to teachers who did not participate in the professional development. Only 10 teachers participated fully and 16 teachers participated partially in this professional development opportunity. This limited sample size reduces the likelihood the results can be translated to the teaching profession as a whole, but does provide useful data to the focus district in the study. Transient students were excluded from this study since their student achievement data would have the additional variables of changing schools and having multiple teachers throughout the multiple years of data. The removal any subgroup population is a threat to the external validity of the study, as the participants involved may not be representative of the larger population. 
Teachers included in this study are from JCPS in Louisville, Kentucky. This urban school district is located near the researcher's home and was selected based on geographical location and personal and professional connections to the district. The researcher worked in JCPS for 14 years as a fifth grade teachers and an instructional technology specialist. Teachers participating in the reform style professional development opportunity volunteered or were suggested by their building administrator. The volunteer nature and commitment to the fidelity of the professional development indicates these teachers already go above and beyond the day-to-day nature of the job, which could have an additional influence on student achievement outside the scope of this study. The reform style professional development focused on CCSS for grades K-5, therefore the study is further limited to elementary teachers. Additionally, Kentucky modified their assessment criteria to assess CCSS in 2012. The classrooms included in this study needed three years of state norm-referenced data under the new accountability standards to conduct the hierarchical linear multiple regression analysis. The only elementary students in JCPS with three years of state norm-referenced assessment data at the time of this study are students enrolled in fifth grade during the 2014-2015 school year. As a result, this study only included fifth grade math teachers, teaching students who have two years of pre-test data, prior to the professional development provided during the 2014-2015 school year. This reduced the scope of the study from the 6,500 teachers teaching in JCPS to the 258 teachers surveyed in this study.

A survey was administered to all 258 , fifth grade math teachers. This included all teachers who attended the professional development and was done so to assess teacher's utility of practices learned in the professional development, and the perceived 
relationship with student achievement. Survey data from teachers not participating in the professional development was collected in an attempt to control for teacher experience, math certification, and years of teaching math. While there are additional non-measured characteristics that inherently exist between teachers in a school district, the researcher chose to focus on the three listed. These inherent differences could contribute to instructional differences between the control group and the reform style professional development group, as well as difference within each group, which are outside the scope of this research study. In addition teacher attrition and teacher transfers reduced the number of classrooms available for this study, as the district only provided assessment data for teachers who were teaching in the fifth grade classroom for the duration of the 2014-2015 school year.

\section{Limitations of the Study}

Limitations are potential weaknesses or problems with the study identified by the researcher and could influence the interpretation of the results (Creswell, 2005). The limitations often relate to inadequate measures of variables, loss or lack of participants, small sample sizes, errors in measurement, and other factors typically related to data collection and analysis. These limitations are useful to other potential researchers who may choose to conduct a similar or replication study. (Creswell, 2005) Future researchers may replicate this study using a rural population to determine if the results vary in a suburban or rural school district. The limitations of this study are as follows. The research study was conducted in only one large, urban school district in Kentucky, which is not scalable to any urban school district. Curriculum variations exist within the 90 elementary schools in JCPS. There are four traditional elementary schools, twelve 
magnet elementary schools, and the remaining schools are not classified as a particular style. Since Kentucky is a Site Based Decision Making (SBDM) state, each of these elementary schools is able to choose their own curriculum for mathematics. While they should all adhere to the district pacing guide for teaching mathematics, the style and curriculum used to teach mathematics differs in each of the schools. These differences provide instructional differences, which are outside the scope of this study.

At the time this study was being undertaken, JCPS was facing high teacher turnover rates and low teacher morale as evidenced by walk-ins to protest teacher salary freezes and unsafe working conditions relating to student behavior. These walk-ins and work-ins, sponsored by the Jefferson County Teachers Union, included teachers participating in this study. The desire to fight for teacher's rights takes time out of their already busy schedules and shows a commitment to the profession that extends into their day-to-day teaching. Teachers participating in this professional development during the school day did so on a volunteer basis. It is difficult for teachers to be out of their classroom for four school days during the school year in order to attend professional development. The teachers participating in this study planned their student's day for the substitute as well as participated in a full day's workshop and met the expectations of sharing the information presented during the professional development with peer teachers in the elementary school they teach. The information obtained from this research can only be generalized to the sample, district, and time period reflected in the data collected.

\section{Design Controls}

In this correlational research study the researcher sought to study the relationship between reform style professional development and student mathematics achievement, 
taking into account pre-existing variables such as ECE eligibility, LEP eligibility, free lunch eligibility, reduced lunch eligibility, and prior year test scores. In an effort to reduce threats to the internal validity of the study, the researcher attempted to control for the following factors impacting both teachers and students. Teachers: Experience (in years), if they hold a math certification, and years of teaching math. Students: ECE eligibility, LEP eligibility, free and reduced lunch status, and prior year test scores. The Research and Development department in the district studied provided the aforementioned student data. Teacher demographics were gathered from teacher survey results (Appendix A).

\section{Organization of Subsequent Chapters}

The following chapters explore the relationship of the CCCSS and reform style professional development with student achievement. Chapter 2 provides a review of the literature starting with the history of standards-based reform movements in the United States, leading into how the CCSS movement began and gained momentum through federal incentives, and lastly illustrating how effective professional development can increase student achievement as well as the defining characteristics research found with effective professional development. Chapter 3 details Research Question 1 and 2 and outlines the procedures of the study including the correlational research design and use of hierarchical linear multiple regression analysis to examine influence of reform style professional development on students' mathematics achievement. Results of the quantitative data analysis, survey results, and student achievement scores are discussed in Chapter Four. Lastly, Chapter Five discusses study findings in consideration of the existing literature, as well as implications this study has on future research and the 
relationship between CCSS, reform style professional development and student achievement. 


\section{CHAPTER 2}

\section{LITERATURE REVIEW}

\section{Introduction}

A flood of evidence amassed over the past decade has contributed to rising concerns about the mathematics achievement of students in the U.S (Darling-Hammond, et al., 2009). This evidence suggests too few students are receiving the high-quality education needed to be college and career ready. In order to propel the United States forward in this global economy we must educate our students in mathematics (McCarthy, 2012). Currently, only half of U.S. $12^{\text {th }}$ graders are able to successfully answer questions calling for "reasoning and problem solving involving fractions, decimals, and percents. Only one in 20 can answer questions calling for reasoning, problem solving, beginning statistics, or probability (PISA, 2012). For many years Title I of the Elementary and Secondary Education Act (ESEA) has required low-performing schools to set aside ten percent of their allocations for school wide professional development to address these deficiencies. This funding has resulted in the allocation of more than three billion dollars to professional development (Darling-Hammond, et al., 2009). More than 40 states have adopted standards calling for effective professional development for all educators accountable for results in student learning. Several national studies on what distinguishes high-performing, high-poverty schools from their lower-performing counterparts 
consistently identify effective school-wide collaborative professional learning as critical to the school's success (Darling-Hammond, et al., 2009). Yet as a nation we have failed to leverage this support and those examples to ensure that every educator and every student benefits from highly effective professional learning to increase student achievement (Yoon, Duncan, Lee, Scarloss, \& Shapley, 2007).

Improving professional learning for educators is a crucial step in transforming schools and improving academic achievement (Yoon, et al., 2007). To meet federal requirements and public expectations for school and student performance, this nation needs to increase teacher content knowledge to ensure that every teacher is able to teach increasingly diverse learners, knowledgeable about how students learn, and competent in the core academic content (Darling-Hammond, et al., 2009). In order to accomplish these goals school systems must ensure the professional learning is planned and organized to engage teachers regularly and to benefit all students. This requires high-quality, sustained professional development throughout the school year. In an effective professional development plan, school leaders learn from experts, mentors, and their peers about how to become instructional leaders (Darling-Hammond, et al., 2009).

\section{The Common Core State Standards: World-Class Standards Movement}

The CCSS represent an unprecedented shift away from disparate content guidelines across individual states and created one cohesive set of research-based standards. The National Governors Association Center for Best Practices and the Common Core State Standards Initiative developed these standards as a state-led effort to establish consensus on expectations for student knowledge and skills that should be developed across grades K-12 (Porter, McMaken, Hwang, \& Yang, 2011). The CCSS for 
mathematics are explicit in their focus on what students are to learn, but not on how that content is to be taught. These standards are internationally benchmarked and have redefined the grade level standards to ensure they are rigorous, clear, and specific (Common Core State Standards Initiative, 2010). These national standards strove to address the issue of some states low expectations for what students should know and be able to do in order to be prepared for post secondary education and the workforce (Rotman, 2012). While a common set of standards existed from National Council of Teachers of Mathematics (NCTM), states were using these standards only as a guide in building their own standards, not as a system to measure student progress. This led to a variety of different standards across the country with different content located at different grade levels depending on which state you were in. The CCSS addressed this unorganized system of standards by ensuring high quality, consistent, and rigorous standards for students, and ensuring they leave school with the ability to apply and articulate deep conceptual understanding of mathematical skills and practices across a variety of new career situations (Conley, 2014). The CCSS provided this single set of high quality standards with the intention for states to use this standard set as the basis for mathematics education.

The Committee of Ten lead one of the earliest national public education initiatives in 1892 by publishing a report entitled The Report of the Committee of Ten on Secondary School Studies. This report attempted to conform high school educational standards to increase rigor and prepare certain students for college (United States Bureau of Education, 1892). The Committee of Ten recommended common standards for English, mathematics, history and sciences, and sought high school and college alignment, both of 
which are the foundation of the most recent Common Core Initiative (Porter et al., 2011). The Committee urged colleges to retain high admission standards, which would in turn force an increase in rigor in high schools (Wallender, 2014). Twelve years of education were recommended, with eight years of elementary education, followed by four years of high school. The committee explicitly addressed student tracking and course differentiation based upon student likelihood of postsecondary purist (Wallender, 2014). The Committee also identified the necessity of highly qualified educators, and proposed that universities could enhance training by offering subject-education courses, and lowering tuition for traveling teachers who could instruct college students aspiring to be teachers.

Educational reform movements continued to strive for higher standards and highly qualified educators in the United States. Public attention to higher standards became apparent in the 1950s when a new set of reformers echoed the Committee of Ten's call for an academically challenging curriculum (Tyack \& Cuban, 1995). This group of key spokespeople consisted of academics and business executives who believed schools were lackluster and anti-academic (Wallender, 2014). They blamed the watered down curriculum, poor discipline, incompetent teachers, and a lack of focus for gifted students. The desire for prepared, successful high school students continued as major justifications for further legislation (Larson, 2012). This public attack on school curriculum further intensified after the launch of Sputnik by the Soviets in 1957 (Tyack \& Cuban, 1995). The Sputnik launch added fuel to accountability concerns as it created a link between education and national security. 
In 1958, President Dwight D. Eisenhower signed the National Defense Education Act (NDEA; New York State Education Department, 2009), which aimed to place additional emphasis on science, mathematics, foreign language, and the other traditional liberal arts in K-12 education. Policy makers wanted rigor, discipline, high cognitive expectations for students, additional training for teachers, and greater regimentation in the classroom (Tyack \& Cuban, 1995). This legislation fused increasing rigor in American schools with preparing students for college to increase global competitiveness and provide national security. To help ensure highly trained individuals would be available to help the United States compete with the Soviet Union in scientific and technical fields, the NDEA included support for student loans to produce more teachers, improve science and mathematics education, and provide additional training for teachers (NDEA, 2015). This was the first educational reform initiative to include high quality teacher training as a way to increase students' mathematics achievement (Larson, 2012).

Educational reform movements redirected again in the 1960s, with ESEA (Tyack \& Cuban, 1995), which strove to provide a high quality education to include all students regardless of gender, disability, or socioeconomic level. Over time ESEA would evolve to include other objectives, such as setting challenging standards, mandating assessments aligned with standards, eliminating achievement gaps and encouraging the use of research-based programs (Crawford, 2011). In conjunction with the 1965 War on Poverty and increased focus on civil rights, the federal government identified public education learning gaps of marginalized groups, such as students of color, special needs students, or English Language Learners (ELL: Larson, 2012). The need to provide quality education for all students advanced and impacted legislation. Through the ESEA of 1965, 
legislators labored to make quality education available and fair to all students (United States Department of Education, 2012). This legislation provided funding for primary and secondary schools under Title III funding to develop innovative ideas to meet the needs of all students (Tyack \& Cuban, 1995). This bill aims to reduce the achievement gaps between students by providing each child with fair and equal opportunities to receive a high quality education. ESEA mandates funds are authorized for professional development, instructional materials, and resources to support educational programs, and parental involvement (United States Department of Education, 2012).

During the late 1970s and 1980s dozens of commissions sought to improve the mediocrity of academic performance, poor discipline, and poor quality teachers (Wallender, 2014). The most influential of which produced A Nation at Risk, which stated education needed to focus on the basics, hard work and competition (National Commission on Excellence in Education, 1983). This report, while politically charged, warned that America's schools were inadequate and not globally competitive (National Commission on Excellence in Education, 1983). A Nation at Risk criticized "equality over excellence" (New York State Education Department, 2009, p.49) by disapproving of the nation's increased efforts toward providing a quality education for all students at the expense of lowered academic standards and achievement. The commission noted the average Stanford Achievement Test (SAT) scores dropped over 50 points in the verbal section and nearly 40 points in the mathematic section from 1963 to 1980 (National Commission on Excellence in Education, 1983). Referencing tests conducted in the 1970s showed on 19 academic tests, students in the United States were never first or second, and in comparison with other industrialized nations, were last seven times. In 
response, the commission made 38 recommendations, divided across five major categories: Content, Standards and Expectations, Time, Teaching, Leadership and Fiscal Support (National Commission on Excellence in Education, 1983). Two of the commission's top recommendations were to strengthen the curriculum with more rigorous standards, and increase teacher competency through effective training models.

The standards-based education outlined in A Nation at Risk (National Commission on Excellence in Education, 1983) was not yet synonymous with creating national educational standards (i.e., common core state standards), but the assertion that "for the first time in the history of our country, the educational skills of one generation will not surpass, will not equal, will not even approach, those of their parents" (National Commission on Excellence in Education, 1983, p.4) managed to strike fear in the American people. Many policymakers began to narrow the currency of educational success to one main measure, test scores, and reduced student achievement to a means of economic competitiveness, both personal and national (Tyack \& Cuban, 1995). A Nation at Risk was only one of many elite policy commissions of the 1980s that declared faulty schooling was eroding the economy and the solution for both educational and economic decline was improving academic achievement. This report further warned that "the United States is falling behind other countries in the resource that matters most in the new global economy: human capital" (National Commission on Excellence in Education, 1983, p. 5). The report recommended states upgrade their standards by adopting a common core of internationally benchmarked standards in math and language arts for grades K-12 to ensure that all students are equipped with the necessary knowledge and 
skills to be globally competitive (National Commission on Excellence in Education, 1983).

This goal of using standards and assessment to increase rigor in schools dominated the administrations of George H. W. Bush, Bill Clinton, and George W. Bush (Wallender, 2014). In 1989, the first national educational summit in over 50 years met to brainstorm national performance goals (New York State Education Department, 2009). This summit laid the groundwork for an effort to improve education nationally, which was spearheaded by organizations representing subject-matter specialists and the National Council on Education Standards and Tests (McDonnell \& Weatherford, 2013). This attempt, called America 2000, introduced in both the George H. W. Bush and Clinton administrations, failed, entangled in controversies over the curricular values underlying state standards and assessments (McDonnell \& Weatherford, 2013). In addition to this focus on national standards, Clinton reauthorized ESEA as Improving American's Schools Act, which expanded the attention on equal standards for all students by creating frameworks for aligning curriculum, performance objectives, assessment, and teacher training (Wallender, 2014). This reauthorization continued the push for highquality professional development for teachers in order to meet the increasing curricular demands for students.

Although these controversies made top-down national standards a non-starter prior to 2000 , the idea of voluntary, shared standards gained momentum with an initiate begun by nine states (American Diploma Project, 2008). In 2001, Achieve, in collaboration with the Education Trust and the Thomas B. Fordham Foundation, established the American Diploma Project (ADP) to ensure that high school diplomas 
signified that students are prepared academically for entry in to higher education and the workforce (American Diploma Project, 2009). These standards were based on surveys of higher education faculty and businesses indicating what knowledge and skills students required to pass college-level courses and workplace training programs. Currently sixteen states align their high school graduation requirements with the benchmarks derived from the surveys (American Diploma Project, 2009). The ADP benchmarks were created to ensure students were ready for college or the workforce, this was considered a separate measure than a proficient score on a state assessment.

In 2001, President George W. Bush proposed NCLB, which was designed to improve the academic performance of children in America's elementary and secondary schools and to ensure that no child is trapped in a failing school. The NCLB act was a reauthorization of ESEA from 1965 and incorporates the following principals and strategies; increased accountability for results from states, school districts, and schools; greater choice for parents and students, particularly those in low-performing schools; more flexibility for states and local educational agencies in the use of federal funds; qualified teachers in their subject areas; and stronger emphasis on reading and mathematics. NCLB required states to create an accountability system of assessments and graduation rates. Schools must make adequate yearly progress (AYP), as determined by the state, by raising the level of academic achievement to a proficiency level that is determined by the state. Additionally, under NCLB, schools are required to use scientifically based research strategies in the classroom and for professional development of staff (NCLB, 2001). NCLB was the culmination of 200 years of policy reform to increase student achievement, improve teacher quality, and increase rigor in schools. 
Education policy leaders are starting to set the final bricks in place to complete a path to a national set of standards whose goal is to educate students who are competitive in the global educational marketplace. The United States would have a set of national standards ready for state adoption nine years following NCLB.

\section{Origins of Common Core State Standards}

In 2006, two former governors, James B. Hunt Jr. of North Carolina and Bob Wise of West Virginia, decided that a common set of national standards, which seemed impossible just a few years prior under NCLB, was now a realistic aspiration (McDonnell \& Weatherford, 2013). In their opinion, policy makers, educators, and the public had now become accustomed to the idea of content and performance standards. Hunt and Wise became the policy entrepreneurs most responsible for persuading key decision makers and constituent organizations to support the idea of national set of common standards as a method of increasing student achievement (Murphy \& Torff, 2014). A significant achievement gap existed between states. Some states expected their students to accomplish far more than other states with much lower standards (Conley, 2014). In essence, what a fourth grader was expected to know in mathematics could vary drastically depending on the state in which she lived. A national set of standards would allow educators to share a common language about what they want students to learn. With the backdrop of students' lack of preparedness for college and careers, governors and chief state school officers continued talking about the need for a common set of high standards (Conley, 2014). In November 2007, state education chiefs met in Columbus, Ohio to discuss the opportunity to collaborate on a single set of world-class K-12 benchmarked standards to college and career readiness. 
The following year the case for common standards was solidified in a report published by the National Governors Association (NGA), the Council of Chief State School Officers (CCSSO), and Achieve, entitled Benchmarking for Success: Ensuring U.S. Students Receive a World-Class Education. This report, guided by an advisory group and published in 2008, drew heavily on research using data from the Programme for International Student Assessment (PISA) and Trends in International Mathematics and Science Study (TIMSS). The report focused on U.S. students' low achievement, compared with international competitors, and documented the achievement gap separating U.S. students from different socioeconomic backgrounds, nothing that the distribution of U.S. students' scores puts the country among the most unequal in the world (McDonnell and Weatherford, 2013). This report grounded its rationale by showing standards in high-performing countries are characterized by focus, rigor and coherence. Following the recommendations of the report, in April 2009 NGA and CCSSO convened governors' education policy advisors and chief state school officers in Chicago to discuss the creation of the Common Core State Standards Initiative. As a result, NGA and CCSSO invited states to commit to a process to develop common standards in English language arts and mathematics.

To embark on this task the committee began researching existing state standards. Research on existing state standards showed dramatic variation between states and significant overlap between grade levels (Porter et al., 2011). Allowing individual states to create standards with varying levels of proficiency left wide gaps in expectations for rigor and student achievement (Murphy \& Torff, 2014). Students scoring proficient in one state could potentially move to another state with more rigorous standards and be 
labeled remedial (McDonnell \& Weatherford, 2013). For example teaching division using the standard algorithm could previously be found in fourth grade, fifth grade, or sixth grade depending on which state standards you view. The variation between states provided little consistency for students moving between states and didn't allow for national teacher education programs that focused on standards.

While addressing the diversity and range of standards existing across the United States, the Council of Chief State School Officers and the National Governors Association joined forces to design standards that are common across all states (Common Core State Standards Initiative, 2010; Wallender, 2014). Development of the standards officially began when 48 states signed a memorandum agreement to participate in developing the CCSS (McDonnell \& Weatherford, 2013). Teachers, administrators, and other professionals collaborated, evaluated feedback from teachers, professional organizations, and the public, and contributed to the development of the English and Language Arts (ELA) and Mathematics CCSS (Common Core State Standards Initiative, 2010). The disciplines of ELA and Mathematics were chosen for common standards initially because they include the skills necessary for all other content areas (Wallender, 2014). The Math CCSS encompass grades K-8, with hierarchical standards provided for High School including, number and quantity, algebra, functions, modeling, geometry, and statistics and probability. There are four to five sub domains for each grade level or content level, and each sub domain contains between 2 and 20 individual standards.

The CCSS were intended to be more rigorous by mirroring the standards of topperforming countries like South Korea, Japan, Singapore, Hong Kong, and Finland (Gewertz, 2013). Development of the new standards was guided with one goal in mind: 
to prepare students for college and careers. The standards were intentionally designed from the top down, starting with over a decade's worth of evidence describing what it takes to be college or career ready (Conley, 2014). This allowed the CCSS designers to map backwards ensuring by the time a student reached High School they covered all skills required to be successful. The CCSS leaders intentionally used research to guide their work to avoid past ideological debates stemming from previous curriculum reforms (Larson, 2012). Every decision was based in research, which successfully curtailed personal beliefs between individuals. For standards where research was not available, the writers used learning trajectories for primary grades and inferences from researchers and mathematicians helped map the content sequentially to support the rigorous and aligned standards they strove to create (McDonnell \& Weatherford, 2013).

The initial drafts of the CCSS incorporated the combined experiences and expertise of teachers, education organizations, and other nations that have sought to raise educational expectations and achievement. These initial drafts, grounded in research and best practices, were provided to all state education agencies, educators, and the public at large for review, scrutiny and comments. The feedback received from these groups resulted in significant revisions and refinements over multiple drafts (Conley, 2014). In addition, a Validation Committee scrutinized the evidence base underlying the CCSS and the process used to develop them. The Validation Committee was appointed by a group of governors and chief state school officers in 2009 , and the Committee members were chosen based on their experience in the development or implementation of national or international standards in education (Porter et al., 2011). After five months of review by the Validation Committee that included group meetings and individual critiques and 
comments, the Committee voted overwhelmingly to confirm that the standards met the validity criteria established by the Committee. The Committee's review process determined that the standards were a valid representation of the knowledge and skills necessary for students to be college and career ready (Conley, 2014). The final version was presented to states in June 2010.

In the fall of 2010, Kentucky became the first of 45 states to adopt the Common Core, making Kentucky, and JCPS, a test case for the standards (Common Core State Standards Initiative, 2010). For Kentucky the standards represented an opportunity to aim again for a long-time goal. Educators had hoped for years to compete with states like Massachusetts and Minnesota, the country's education elite. Working towards increased student achievement for the past two decades, Kentucky had undertaken an ambitious education overhaul, the Kentucky Education Reform Act (KERA). This reform bill introduced new standards and assessments, which unfortunately failed to catapult the state to the top (Butrymowicz, 2013). A recent report entitled, The State of State Standards - and the Common Core (2010), by the Thomas B. Fordham Institute, a conservative think tank, gave Kentucky's previous ELA and math standards, Kentucky Academic Standards 4.1 a D. Only 11 other states were rated as poorly or worse in both subjects. This poor ranking on a national level marked the end of KERA's curricular goals and the foundation for these new more rigorous standards.

In April 2009, a Kentucky state law mandated the development of more rigorous educational standards and the adoption of a new K-12 state assessment to match these new standards. The Kentucky Academic Standards 4.1 were no longer considered sufficient. Shortly after the passing of Senate Bill 1, the architects of the Common Core 
began working on the national standards. Kentucky state officials expressed interest early on, and frequently provided feedback regarding the CCSS (Butrymowicz, 2013). In 2010, although the standards had not yet been completed, the Kentucky state board of education voted to adopt them. The completed Common Core standards received an A- in math and a B+ in English from the Fordham report, a significant curricular increase from the preexisting Kentucky state standards D score. The Kentucky state education commissioner said, in a videotaped interview in 2011, "our teachers are going to need a lot of help. It's hard work, but it's the right work, at the right time, for the right people" (Butrymowicz, 2013, p. 87). Implementing new Math and ELA standards on such short notice was overwhelming for the state's 174 school districts and 47,000 teachers. Planning and informational sessions began immediately (Kentucky Department of Education, 2014a).

Throughout the summer of 2011, Kentucky hosted a series of regional trainings where representatives from school districts could learn more about the standards and how to inform their colleagues. No extra funding was allocated to districts to help them prepare for Common Core or fund the professional development needed to fully implement the new standards (Butrymowicz, 2013). Some districts throughout the state used grant money to pay teachers to compare Common Core Standards to the state's old standards, revise their district's curricula, and identify gaps in curriculum programs. Bringing the state's 47,000 teachers up to speed on the new standards, and helping them translate those ideas into curriculum for the classroom would require both time and money (Gewertz, 2010). The first state assessments based on the CCSS were administered in the spring of 2012. This occurred at the end of the first full year of CCSS implementation. Testing students on the more rigorous standards produced predictably 
lower test results (Butrymowicz, 2013). Proficiency ratings, for students in grades 3-8, were about 30 percentage points lower in math than they were the year before. The largest drop occurred at the elementary level, in 2010-2011,73 percent of elementary students were proficient or better in math, but that fell to 40.4 percent under the new assessment and accountability system (Kentucky Department of Education, 2014b). A similar drop was noted in New York in 2013, when it became the second state to test under the new standards. Research has shown, in order to move more students to proficiency, effective professional development must be provided to teachers to increase content knowledge and content specific instructional practices (Yoon et al., 2007).

\section{Common Core State Standards Adoption}

Continuing along the path of his three predecessors, President Obama has stated a strong commitment to academic standards as a fundamental element of his educational reform agenda. It is unconstitutional for the federal government to mandate CCSS adoption; therefore individual states voluntarily adopted the standards (Common Core State Standards Initiative, 2010). As an incentive to expedite the process, the federal government allocated some of the RTTT point allocations to the adoption of the CCSS (United States Department of Education, 2013b). This 2010 initiative from the U.S. Department of Education offered states the chance at four billion dollars in grants if they adopted certain education-improvement criteria. This structure afforded 70 points or $14 \%$ of the total score, to states that adopted the CCSS. Many states, but not all, chose to adopt the CCSS around the time of this incentive (Conley, 2014). At the time of this paper, forty-three states, the District of Columbia and four territories are currently teaching based on the CCSS (Common Core State Standards Initiative, n.d.). The push from the 
federal government, along with financial incentives through RTTT, has given the federal government unprecedented influence over the curriculum and pedagogy of the nation's schools (Wallender, 2014).

In seeking to close the global achievement gap, U.S. schools have adopted the Common Core standards, built firmly upon the tenet of inquiry (Mathis, 2010). According to Douglas and Hortsman (2011), it is understanding the strategies used and defending the justification in reasoning that will provide students with the growth we seek in mathematics. It is the responsibility of the teacher to pose insightful math problems, then skillfully probe and facilitate productive group work, speaking "mathematically," in order to enable students to make connections to concepts (Douglas \& Hortsman, 2011). Today's instruction should focus on preparing students to produce accurate responses and to choose and implement an appropriate and expedient strategy (Kornhaber, Griffith, \& Tyler, 2014). Through consistent analysis of what high quality student work looks and sounds like, educators will be able to work smarter, not harder. Wagner (2012) also valued the practice of dissecting the work produced by students in order to determine the effectiveness of instruction and provide clear evidence of skill mastery. Teachers, administrators, and coaches who establish and share common roles and best practices realize what it possible for all children to achieve in the Twenty-First Century (Confer \& Ramirez, 2012).

As states are adopting the CCSS, policy makers chose to downplay the fact that all researchers would say with any certainty is, at best, common standards might be a necessary, but not sufficient way to improve educational outcomes (McDonnell \& Weatherford, 2013). Cohen and Moffitt (2009) believe the lack of system capacity and 
supports for teachers and students are detrimental to a successful implementation of CCSS. To properly implement a new standards-based reform teachers must have professional development outlining the envisioned curriculum and instructional materials to ensure confidence in teaching these new standards (McDonnell \& Weatherford, 2013). This would provide the resources necessary for teachers to increase student achievement. Policy makers chose to ignore the professional development aspect of the CCSS initiative, they didn't want to complicate the agenda since the financial burden of professional development would fall to the individual districts (Common Core State Standards Initiative, 2010). The success of this standards-based reform hinges on effective professional development to change instructional practices in the classroom to achieve fidelity with the CCSS.

\section{The Role of Professional Development in Advancing Educational Reform}

Research shows there are four elements to establishing the empirical link between professional development and student achievement (Yoon et al., 2007). These include: (a) a rigorous research design that ensures the internal validity of causal inferences about the effectiveness of professional development. If the study design consists of strong internal validity, this can rule out competing explanations for gains in student academic achievement. The research design should be able to measure the value that professional development adds to student learning separately from the value added by innovative curriculum, instruction, or materials. A rigorous research design will also have externally valid findings, adequate statistical power to detect true effects, and sufficient time between the professional development and the measurement of teacher and student outcomes; (b) the study design will be executed with high fidelity and sufficient 
implementation of professional development; (c) psychometric properties of measures will be adequate (measures of classroom teaching practices, of student achievement, and of teacher knowledge, beliefs, and behaviors). These measures should be valid, reliable, age-appropriate, and aligned with the professional development; (d) analytical models will be well specified and statistical methods will be appropriate. Given these requirements, it is not surprising there are few studies on the effects of professional development on student achievement.

The 1996 report What Matters Most: Teaching for America's Future concluded what teachers know and do is the most important influence on what students learn. The most direct way to improve the quality of education is therefore to improve the knowledge base of teachers, and to provide professional development opportunities, which help teachers better facilitate student learning (National Commission on Teaching \& America's Future, 1996). This includes professional development activities, which are of high quality, sustained over time, intensive, and classroom focused in order to have a lasting impact on classroom instruction (Hirsh, 2006). Teachers, unlike other professionals, improve their instructional methods or content knowledge in isolation (Hirsh, 2009.). Research suggested that when teachers attend one-day workshops, they would incorporate less than $10 \%$ of what they learn due to a lack of follow up after the workshop (Hirsh, 2009). Teachers that use strategies which include examining data on student's performance, studying content and instructional strategies aligned to student standards, designing joint lessons, and creating formative assessments that enable them to measure the impact of the lessons will increase student achievement (Hirsh, 2009). Teachers in Europe and Asia spend 15-25 hours per week in joint planning and 
collaboration, this is approximately five times the amount U.S. teachers spend (DarlingHammond \& Richardson, 2009). Higher expectations for student performance and increased accountability standards like the CCSS, have shifted professional development from what teachers want to what students need (Hirsh, 2009). In order to reach new accountability standards, professional development based on an analysis of student data and focused on a set of activities designed to coach and provide feedback, will ensure effective classroom implementation of new curriculum. The focus of professional development moves from teacher training to continuous teacher learning (Hirsh, 2009).

The United States spends up to $\$ 14$ billion on teacher education annually, yet little has been done to effectively evaluate instructional practices in our nation's schools (National Institute for Excellence in Teaching, 2012). In order for the CCSS to influence classroom instruction in the United States in a widespread and sustained way, schools and districts must provide opportunities for teachers to participate in high-quality, comprehensive professional development (Youngs, 2013). Continuous professional learning opportunities are critical for the success of reforms in education designed to improve teaching and learning (Torff \& Byrnes, 2011). Teachers should be provided with continuous opportunities to cultivate and refine their teaching practices, while building upon their existing knowledge bases, in order to ignite and inspire learning among their students (NCTM, 2014). Many districts and states are overwhelmed by the scope of teacher training required to launch the new CCSS (Anderson \& Herr, 2011). Despite the identification of professional development as a central feature of improvements in public education, the majority of programs have been criticized as low in quality (Torff \& Byrnes, 2011). The common practice of teacher professional efforts that lack connections 
and are not research based, result in minimal sustained change. This demonstrates the need for teacher training opportunities capable of altering the culture of the classroom and focus on teaching practices that enhance student achievement (Torff \& Byrnes, 2011).

Although teachers generally support the high standards for teaching and learning CCSS provide, many teachers are not prepared to implement high quality instructional practices based on those standards (Garet et al., 2001; Snow-Renner \& Lauer, 2005). Many teachers learned how to teach using a model of teaching and learning that focuses heavily on memorizing facts, without also emphasizing deeper understanding of subject knowledge (Garet et al., 2001). Shifting to a more balanced approach to teaching, which places emphasis on understanding subject matter, means that teachers must learn more about the subjects they teach, and how students learn theses subjects. The continual deepening of knowledge and skills is an integral part of the teaching profession (Garet et al., 2001). To deepen teachers knowledge of how students learn mathematics and what the CCSS and instructional shifts in mathematics mean for their students, teachers must be exposed to these practices and involved in discourse with peers and curricular leaders (Tyminiski, 2009). In order for shifts in practice to go beyond short-term changes, districts need to ensure follow-up and evaluation of the new teaching and the professional development itself (Fancella, 2010). In lieu of one-shot workshops or isolated conferences, teachers should learn on the job, through collaborative, job-embedded, sustained professional development (National Institute for Excellence in Teaching, 2012). Effective teacher training should contain elements of collegiality within the learning environment, as well as support throughout the implementation phase (Esqueda, 
2008). Math teachers specifically, need to be afforded ample opportunities for collaboration with other teachers in the analysis of student work, identification of student mathematical reasoning, and discussion and reflection of instructional methodologies aimed to promote student understanding (National Institute for Excellence in Teaching, 2012). Professional growth takes place when instructors come together on a continuous basis to examine student learning and the impact of their own methodology (NCTM, 2014). Singh, Yager and Yukaton (2011) identified successful math professional development as less focused on the individual, and more focused on collaborative group learning. Additional components of effective teacher learning opportunities included long-term over short term, more emphasis on the teacher as a producer of knowledge versus consumer, and active learning versus passive knowledge acquisition (Singh et al., 2014) The National Institute for Excellence in Teaching (2012) stated the determining factor of professional learning effectiveness is not the professional development itself, but "the conditions under which it was delivered." Professional development for teachers is a key mechanism for improving classroom instruction and student achievement (Cohen \& Hill, 2001; Darling-Hammond \& McLaughlin, 1995). While calls for high quality professional development are perennial, there remains a shortage of such programs, characterized by coherence, active learning, sufficient duration, collective participation, a focus on content knowledge, and a reform rather than traditional approach (Garet, et al, 2001). A particular target for criticism is the prevalence of a one-day workshop that often makes teacher professional development disconnected from deep issues of curriculum and learning, fragmented and noncumulative (Garet et al., 2001). 
One rigorous quantitative study described a meta-analysis of 1,300 research studies and evaluation reports from which researchers identified nine experimental or quasi-experimental studies using control groups with pre- and post-test designs that could evaluate impacts of professional development on student achievement (DarlingHammond, et al., 2009). Their analysis indicated the Unites States has made some progress in certain areas, such as the availability of mentoring programs and an increased emphasis on building teachers' content knowledge. However, the structures and supports needed to sustain teacher learning and change and to foster job-embedded professional development in collegial environments fall short. The time and opportunities essential to sustain professional development with regular follow-up and reinforcement are simply not in place in most school districts, as evidenced by the short duration of most professional development sessions. This study focused on reform professional development that included these four principals: (a) professional development should be ongoing and connected to practice; (b) should focus on student learning and address the teaching of specific curriculum content; (c) should align with school improvement priorities and goals, and; (d) should build strong working relationships among teachers (Darling-Hammond et al., 2009). This study showed that the test group whose teachers were subjected to professional development, which employed the reform characteristics of professional development, the students grew academically at a greater rate than those who did not utilize the reform model characteristics of professional development (Darling-Hammond, et al., 2009; Dever \& Lash, 2013). While casual relationships are not fully established, the researchers found that some basic principals for designing professional learning that school and district leaders should consider. Garet et al. (2001) 
also found student achievement could be increased if the delivery of professional development focuses on increasing teacher content knowledge and understanding how students learn.

Torff and Byrnes (2011) found professional development programs were awarded higher ratings when sustained, focused, intensive, meaningfully integrated into school culture, and containing hands-on, active learning activities for teachers. Teacher training should help educators to acquire pedagogical knowledge and content area knowledge through analysis of examples, representations, and explanations related to student thinking, understanding, and misunderstandings (Youngs, 2011). Professional development should include time for teachers to meet in collaborative teams in order to focus on specific student needs over a sustained period in order to collectively determine the instructional solutions that will provide measurable growth in student learning and achievement (National Institute for Excellence in Teaching, 2012). Through participation in these intentionally created communities of practice, teachers are able to connect to math in new ways through discussion, analysis, observation, and reflection (Gellert, 2013). It is through communities of practice that elementary school educators develop more positive mathematics identities, socially constructing feelings of competence that release feelings of discomfort pertaining to teaching math at deeper levels as well as their own negative experiences with math. (Confer \& Ramirez, 2012; Gellert, 2013). Teachers are challenged by the new CCSS in that they are being asked to teach using math methodology they never experienced as students (Confer \& Ramirez, 2012). Through group discussions, math teachers should identify given concepts, then ask themselves: What should students know and be able to do? (Kornhaber, Griffith, \& Tyler, 2014). 
Michalec (2013) cautions districts to ensure teacher training does not limit the professional autonomy of teachers through prescriptive instruction. Rather, teachers participating in professional development should have time to talk through areas of frustration as well as successful experiences with various instructional practices to enhance student outcomes (Michalec, 2013).

The current shift in teaching resulting from implementation of the CCSS emphasizes student learning and outcomes as opposed to teacher actions and performance (Reeves, 2011). Confer and Ramirez (2012) worked as math instructional coaches in high-poverty Arizona public schools, where they discovered few teachers today learned math on a conceptual level when they were elementary students, resulting in few positive experiences with math as adults. The challenge for educators with the adoption of the CCSS is that they are being asked to teach math using methodology they never experienced as students (Confer \& Ramirez, 2012). The shift for elementary math teachers stems from instruction built upon conceptual knowledge as opposed to solely procedural knowledge (Holmes, 2012). Procedural knowledge embodies information gained through algorithms, procedures, memorization of rules, or symbolic representations, while conceptual knowledge embodies deeper understanding of the relationships among principles and concepts (Holmes, 2012).

The missing element for educators in the twenty-first century is how best to create clear learning goals and objectives to drive instruction and assessment to better identify demonstrated student learning (Reeves, 2011). Bostic and Matney (2013) conducted a study of 469 elementary teachers to determine how best to support educators in implementation of Common Core math standards. The researchers used teachers' 
perceived needs as a key rationale for the structure and content of professional development provided during the study. Findings indicated that teachers desired assistance in utilizing instructional strategies designed to foster math-reasoning skills and to support students' conceptual development of mathematical skills (Bostic \& Matney, 2013). The researchers concluded when developing CCSS focused professional development, teacher's perceived needs around pedagogical and content-area must be considered to influence student achievement. These findings played a significant role in the planning and development of the reform-style professional development implemented for this study.

The research studies presented above show effective professional development can potentially increase student achievement, but proving that professional development will translate into increased student achievement poses challenges (Yoon et al., 2007). The link between professional development, teacher learning, student learning and student achievement needs more research. Teacher professional development affects student achievement through three areas: teacher knowledge, teacher skills, and teacher

motivation. As teachers improve their knowledge and skills, motivation to improve will enhance classroom teaching and improve student achievement (Yoon et al., 2007).

\section{Summary of Literature Review Findings}

The CCSS initiative marked a landmark curricular reform for grades K-12. Beginning as early as 1892 , many U.S. initiatives and considerable legislation laid the foundation and provided momentum for the creation of the CCSS. Although there were many reasons for these initiatives and legislation, four salient justifications were evident in the literature: creating common educational standards, preparing students for college, 
stressing quality education for all students, and increasing rigor in schools. Throughout U.S. public education history, various combinations of ideas impacted past initiatives and legislations, but the CCSS successfully united all four justifications. The CCSS brought philosophical, curricular, instructional, and assessment changes to public education. Informed educators can generate more thoughtful and balanced discussion among stakeholders by becoming aware of the historical underpinnings leading to this momentous initiative (Common Core Standards Implementation Can Lead to Improved Student Achievement, 2012). The CCSS are not such a radical departure that they require educators to start from scratch and redesign all that they do. The CCSS organize and sequence content in ways that lead toward all students being college and career ready, and they do so by focusing on key content and by setting higher expectations. In this sense, the CCSS encourage best practices in teaching and learning. Educators build on their current effective methods to implement the CCSS in ways that make the most sense for the students in the classroom (Conley, 2014). Knowing where the CCSS expect more and different thinking from students is important as curriculum developers, teachers, and others begin to translate the standards into practice. This knowledge helps all students achieve the fundamental goal of the CCSS, to be college and career ready. Professional development providers at the school and district level should compare their old state standards to the new CCSS. That analysis will help professional development providers, content specialists, and teachers decide how to best arrange their classroom lessons to align with the new standards. The best student outcomes occur when teachers and curriculum specialists develop a locally approved and implemented curriculum (Conley, 2104). 
This literature review has focused on the century long design of CCSS, the incentives that have pushed this quick adoption of national standards in response to low mathematics achievement in the United States, and the need for high-quality professional development. This literature review is by no means an exhaustive study. It does, however, provide a foundation for the scope of this research project. Ultimately, the research in this study focuses on the need for teachers to understand the research behind the development and subsequent adoption of the CCSS for teachers to potentially produce change in instructional practice and student achievement. The goal of implementing CCSS in conjunction with professional development is to have a positive impact on student achievement. This study seeks to examine if reform style professional development in a large urban school district has a positive relationship with student mathematic achievement.

The CCSS movement stands to be one of the most significant movements in public education during our lifetime. It is the latest in a long line of educational reform measures in the United States to evaluate student achievement. From the Committee of Ten Report to the NCTM Standards based reforms of the past several decades, policy makers have attempted a number of methods to better education students. With the current adoption of CCSS, $87 \%$ of the US population is learning from a common set of standards (Common Core State Standards Initiative, 2010). The impact of CCSS should be studied closely, with regular review and revision as further input from various populations and research findings continue to inform education and professional development. The efforts of the CCSS to standardize curriculum is unprecedented in nature and provides opportunities for multiple stakeholders to work toward a common 
goal of increasing student achievement. The purpose of this study was to examine the relationship of reform style, CCSS focused, instructional strategy based, professional development and student achievement in JCPS, a large urban school district in Kentucky. It was the researcher's hope that by adopting the CCSS and providing teachers targeted, high quality professional development, there would be a significant positive relationship with student achievement, and a lasting influence on teacher's instructional practices in the classroom. This would provide sound evidence to continue to provide reform style professional development, considering extended and continuous professional development is more expensive to implement. The results of this study may offer new information related to the following Research Questions:

Research Question 1: Is reform style professional development positively associated with students' mathematics achievement?

Research Question 2: What are teacher's perceptions of reform style professional development's effectiveness on their instructional practices and student achievement? 


\section{CHAPTER 3}

\section{METHODOLOGY}

The purpose of this study was to examine the relationship of reform style, CCSS focused, instructional strategy based, professional development with student achievement in JCPS, a large urban school district in Kentucky. The researcher compared the academic achievement of students in classrooms with teachers who participated in a year long, reform style professional development opportunity, students whose teachers partially participated in the professional development, and those students whose teachers did not participate. This study was conducted in JCPS, a large urban school district of 101,000 students. All teachers included in the study were invited to completed a survey to identify demographic data, teachers participating in the professional development were asked to answered additional questions, which explored the lasting effects of the reform style professional development on their day-to-day instructional practices. This chapter describes the research design, participants, instrumentation, data collection methods, and methods of analysis used in this study.

\section{Research Questions}

The results of this study may offer new information related to the following Research Questions: 
Research Question 1: Is reform style professional development positively associated with students' mathematics achievement?

Research Question 2: What are teacher's perceptions of reform style professional development's effectiveness on their instructional practices and student achievement?

\section{Research Design}

This study sought to examine if the inclusion of focused and effective professional development during the 2014-2015 school year positively promoted student mathematics achievement in the classrooms of teachers who attended. This was achieved by examining the norm-referenced (Part A) section of the state's standardized assessment to measure student achievement. With the development and adoption of CCSS in 43 states (Standards in your state, n.d.), it is critical to determine if this standards-based reform has increased student achievement for our students. There is a general agreement with researchers that the CCSS will not result in learning gains unless they are accompanied by effective professional development, state-of-the-art assessments, and aligned curricula and instruction (King, 2011).

To address Research Question 1 and determine the relationship between reform style professional development on mathematics student achievement, a correlational research design was used (Creswell, 2005). This study sought to determine if there was a significant difference in the academic achievement of students whose teachers participated in a year long, reform style professional development opportunity compared to those students whose teachers did not participate in the professional development. Scores of students enrolled in these classrooms were compared in this retrospective analysis of standardized achievement test scores. Even though this design cannot provide 
for a direct test of causation, it can provide information to support or refute causal explanations. In this case, achievement test scores were collected from student records and comparisons were made between those students whose teacher participated in the reform style professional development, those who participated partially, and those who did not participate. Findings could suggest a link between professional development design and mathematics achievement.

Following the Institutional Review Board (IRB) approval from the University of Louisville to conduct this study, the researcher applied to the IRB with JCPS. Student achievement data for mathematics, from the 2011-2012, 2012-2013, and 2014-2015 school years were requested for students enrolled in fifth grade during the year of 20142015, the year the reform style professional development took place. Student demographic data for ELL eligibility, ECE eligibility, free lunch eligibility, and reduced lunch eligibility were requested via the district's IRB process. JCPS approved the study's exempt application within a week and provided the data requested in only five days, frequently checking with the researcher on the layout and quality of the data.

To address Research Question 2, teachers who participated in the professional development were invited to complete a survey to gather their opinions on if this professional development provided a lasting influence on their instructional practices. This survey (Appendix A) was sent out to all fifth grade teachers for the 2014-2015 school year. Teachers had the option to complete the survey and many chose not to provide additional information on how this professional development frames their current instructional practices. Lynn Smith, the elementary math specialist for Jefferson County Public Schools, sent the survey to teachers via district e-mail (Appendix A). It was the 
researcher's hope receiving the survey from the Instructional Specialist responsible for planning and delivering this professional development would increase the response rate. The survey was housed on Google Forms and only the researcher had access to the data once teachers completed the survey. While the survey requested the teacher's email address, which would provide their full name due to the first name, last name format of the district's email address, the researcher did not include this in any of the analytics or communications with the district following the study.

The theoretical framework for this study focuses on outcomes-based education (OBE), which is comprised of four principles (Kilen \& Hattingh, 2004). The first principle is clarity of focus, the belief that education systems should be organized so that teachers and learners can focus clearly, consistently, systematically, and creatively on the important outcomes that learners are to achieve. The second principle is called designing back, which states the starting point for curriculum design must be a clear definition of the significant learning that students are to achieve. There should be direct and explicit links between all planning, teaching, and assessment decisions and the significant outcomes that students are ultimately to achieve (Kilen \& Hattingh, 2004). The third principle of OBE is that teachers should expect all students to achieve significant outcomes to high standards. Depth of understanding and intellectual rigor is expected of all students (Kilen \& Hattingh, 2004). The fourth principle is that teachers must strive to provide expanded learning opportunities for all learners that recognize not all students can learn in the same way and in the same time (Kilen \& Hattingh, 2004). 


\section{Sample}

This study was conducted in Jefferson County Public Schools, which is a large urban school district in the southeastern United States. JCPS contains 89 elementary schools teaching students in grades K-5, and one school with students K-12. The student enrollment of all elementary schools for the 2014-2015 school year was 41,657 (JCPS at a glance, n.d.). The average spending per student at the elementary level is $\$ 9,763$. The racial make-up of JCPS is $50.8 \%$ white, $36.3 \%$ African American, 5.4\% Latino/a, 4.3\% other, 2.8\% Asian and .1\% American Indian (District Fact Book, 2011). More than 60\% of all students receive free lunches, while $67.5 \%$ of elementary students receive free or reduced lunches. During the 2009-2010 school year, 10,497 students were considered homeless at some point during that school year, JCPS had 13,638 students are labeled as special needs or having an Individualized Education Plan, and 5,255 students classified as English Language Learners. The average student attendance rate for elementary students is $93.9 \%$ (JCPS, 2011).

This study included third grade students during the 2012-2013 testing year, fourth grade students during the 2013-2014 testing year and fifth grade students during the 2014-2015 testing year. These students are included in the study since they are the only group with three years of K-PREP assessment data for the study. This encompasses 7\% of the total population in this school district. For this study the norm-referenced component of the K-PREP Kentucky state assessment (Part A), for mathematics was used to measure student achievement. The researcher used the raw score from the normreferenced assessment since it provides equal intervals between each numerical score. Students attending more than one school were excluded from this study since their test 
scores could have significantly more variables attached to them with multiple schools and multiple content delivery methods. In addition students who do not have three years of achievement data were excluded from the study. The researcher attempted to control for teacher variables including years of experience, years teaching mathematics, and math certification.

With seven predictor variables, the 6,142 cases used in this study well-exceeded established sample-size guidelines for hierarchical linear multiple regression (Preacher, Curran \& Bauer, 2006). For overall fit of a regression model with seven predictors, a minimum sample size of $106(50+8 k$, where $k$ is the number of predictors $)$ is required (Field, 2005). For testing individual predictors, a minimum of $111(104+k)$ cases were needed (Field, 2005). To achieve a high level of power, 80, 200, and 600 cases are needed for large, medium and small effect sizes respectively (Field, 2005). There were 596 student achievement scores for teachers fully participating; 584 student achievement scores for teachers partially participating; and 4,962 student achievement scores for teachers not participating. Teacher participation was selected using a sampling of all fifth grade teachers in the district. The researcher sought to include all potential subjects as part of the sample. Professional development participation records were pulled from JCPS' PD Central Database to indicate how many professional development sessions each teacher participated in. The survey went out to all fifth grade teachers, for the 20142015 school year, in the school district's 90 elementary schools. This non-probability sampling technique is considered the best of all non-probability samples since it includes all subjects whom are available, which makes the sample more representative of the entire population of the district (Explorable, 2009). 


\section{Instrumentation}

The variables for this study are as follows. The independent variable at the teacher-level was teacher participation in reform style professional development. Teachers must attend $50 \%$ or more of the offered sessions to be included in the study as fully participating; attending one session was considered partially participating. The student-level independent variables are ECE eligibility, LEP eligibility, free lunch eligibility, and reduced lunch eligibility. The dependent variable for this study was student mathematics achievement based on the norm-referenced component of the state standards K-PREP assessment. Senate Bill I (2009), enacted in the 2009 Kentucky General Assembly, required the new K-PREP assessment program to begin assessing the CCSS in the 2011-2012 school year (Kentucky Department of Education, 2014b). The assessment for grades three through five is a blended model built with norm-referenced test (NRT) and criterion-referenced test (CRT) items, which consist of multiple-choice, extended-response, and short answer items. The norm reference part of the test is a purchased test with national norms. Pearson has been awarded the contract to provide all Kentucky assessments for grades three through eight and writing on-demand at high school. Pearson currently provides large-scale assessment services in 25 states and for the U.S. Department of Education (Kentucky Department of Education, 2014b). Students were provided 40 minutes to complete Part A of the K-PREP assessment, which consisted of 30 multiple-choice questions (Kentucky Department of Education, 2014b). Part B and C of the K-PREP math assessment are criterion referenced and not used for this study. Part B consisted of 27 multiple-choice questions, two short answer questions, 
and one extended response. Part C consisted of 10 multiple chose questions and one short answer question.

Quality control for the psychometric analysis consists of inspecting student data for completeness and accuracy of data, omissions, and other data issues are investigated before subsequent analysis (Kentucky Department of Education, 2014b). Item scores are inspected using statistical key checks that compare the distribution of student responses to predetermined criteria. Item calibrations and scaling are performed by two independent replications of Pearson staff and one external consultant. The results are compared for consistency (Kentucky Department of Education, 2014b). The norm-referenced portion of this math assessment consists of test content from the Stanford Achievement Test Series, Tenth Edition (Kentucky Department of Education, 2014b), which uses existing score norms to report local student achievement on a national scale. This study pulled the raw score for this assessment; the reason for this was percentile rank score ranges from one through 99 where the value of 50 reflects typical performance in a nationally representative sample of students at the grade level of interest. Percentile ranks are useful to show student performance as compared to other students in a particular reference group; however, they are not equal units across the scale so this study used the raw score. The Kentucky Department of Education establishes the validity of this assessment and accountability program by comparing studies researching the consistency of student results across multiple measures, the congruence of student scores with documented improvements in instructional practices and the school learning environment, and the potential for all scores to yield, fair, consistent, and accurate student performance. These 
third-party research documents provide evidence to assess the validity of each component of the statewide testing program (Kentucky Department of Education, 2014b).

Norm-referenced test (NRT) scores in the area of math were used as the measure of student achievement for this study. NRTs are tests which report whether test takers performed better or worse than a hypothetical average student, which was determined by comparing scores against the performance results of a statistically selected group of test takers, typically of the same age or grade level, who have already taken the exam. These kinds of tests/assessments differ from criterion referenced tests in that scores reflect students' academic standing relative to other students, rather than their proficiency on particular educational standards. NRTs are developed and used to place individuals along a normal curve in comparison with others in a sample population. In general, a NRT was designed to achieve a range of scores in order to maximize the separation of individuals along a continuum of some ability. How well each person does in the normative sample will affect the standing of others in the standardization group. NRTs answer where does this person place as compared to his or her peers. The NRT scores in this study are associated with the teacher of record for math in the school they attended during the 2014-2015 school year.

\section{Data Collection}

Approval to conduct this study was obtained from the University of Louisville and the Jefferson County Public Schools as an exempt study. Written permission to conduct this study as obtained from authorized personnel from the University of Louisville and Jefferson County Public Schools (Appendix B). Data collection began in March of 2015. The research and development department in JCPS provided student 
achievement data from the norm-referenced math section of the state assessment for all third grade students for the 2012-2013 school year, all fourth grade students for the 20132014 school year, and all fifth grade students for the 2014-2015 school year. In addition the research and development department provided demographic data for these students, including English language learners and free and reduced lunch status. Free and reduced lunch status was recorded as free (1), reduced (2), or paid (3). The district coded student identities as numbers ranging from one to 22,308 to protect the privacy of all students.

Teacher participation in the reform style professional development was obtained from the JCPS' electronic professional development database, PD Central. This database provided all fifth grade teacher names as well as the attendance records for all reform style professional development sessions they attended through the 2014-2015 school year. The maximum possible number of sessions was four, six-hour sessions. For the purpose of this study, teachers must have attended two to four sessions to be included in the study as a participating teacher. Teachers who participated in one session are identified as partially participating; teachers who did not attend any sessions are identified as non-participating.

This research study used a cross-sectional survey design approach to gather teacher demographics and teacher perceptions of the professional development provided. A cross-sectional survey allows the researcher to collect data "at one point in time" (Creswell, 2009, p. 146). For this study the cross-sectional survey examined teacher perceptions about the professional development and its lasting implications on their instructional practices. Data was collected using an electronic survey (see Appendix A) sent to all fifth grade teachers in JCPS during the 2014-2015 school year. Teachers 
received the survey through their district e-mail account from Lynn Smith, the district elementary math specialist. The use of the Internet for the collection of electronic data is common and provides a quick and easy form of data collection (Dillman, 2007).

Survey data was collected via an electronic Google Form survey. This survey was emailed out to all fifth grade teachers from the 2014-2015 school year. Teachers were asked to provide basic demographic data and answer questions regarding math certification, years of experience, and years teaching math in an attempt to control for teacher variables. Sample questions include; (a) Including this school year, how many years have you been at your current school, (b) Including this school year, how many years have you been employed as a teacher. This survey asked additional questions of participants of the professional development to determine how effective they feel the opportunity was for them and if they continue to use the strategies taught during this professional development in their classroom. This study asked four questions in an attempt to control for teacher demographic differences, these included; What is your highest level of education; During the last school year what content area was your primary teaching responsibility; including this school year, how many total years have you been employed as a teacher; and do you have a math certification. Teachers who participated in the professional development, either fully or partially, were asked to answer an additional six questions to determine teacher perceptions on the effectiveness of the professional development on their classroom instruction and student achievement. The survey used is provided in the Appendix (Appendix A). 


\section{Data Analysis}

As an initial step in the data analysis, descriptive statistics were used to understand the characteristics of the population being studied. This data included student demographics, the number of students each teacher was responsible for mathematics instruction during the 2014-2015 school year, and the number of students taking the KPREP assessment in 2013-2014 and 2014-2015. Data used in the statistical analyses for this study was collected from standardized mathematics assessment scores, the district professional development database, demographic data from JCPS indicating student eligibility for ECE, LEP, and SES, and additional teacher survey data. Descriptive statistics are reported for the aforementioned sub groups indicating student achievement means and standard deviation within each subgroup.

To determine if reform style professional development had a significant positive relationship with student achievement, a hierarchical linear multiple regression analysis was used to determine which student group, if any, achieved significant gains during the 2014-2015 school year. A hierarchical linear multiple regression model is often used in testing theoretical assumptions and examining the influence of several predictor variables in a sequential way, such that the relative importance of a predictor may be judged on the basis of how much it adds to the prediction of a criterion, over and above that which can be accounted for by other important predictors (Stephens, 2012). Hierarchical multiple linear regression was selected as it is the preferred modeling approach when the research question seeks to address the extent to which a group of variables contribute to the explained variance of the outcome after accounting for the variance attributed to covariates (e.g. student demographics). Using the hierarchical linear multiple regression 
model the researcher attempted to control for differences in student characteristics. Student achievement scores were divided into three groups: teachers who participated with fidelity, teachers who partially participated, or teachers who did not participate to determine which group or groups, produced a significant positive relationship with student achievement. Three variable blocks of predictors were used in this hierarchical linear multiple regression; (a) student demographics: free lunch eligibility (Eligible $=1$ ), reduced lunch eligibility (Eligible $=1)$, LEP eligibility $($ Eligible $=1)$, and ECE eligibility (Eligible $=1)$; $(b)$ prior year test scores; and (c) teacher participation in professional development, either partial $($ Partial $=1)$ or full $($ Full $=1)$ participation. The first block served to control for student demographics prior to the entry of the second block to control for prior year test scores, and the third block that contains teacher groups based on participation in professional development.

The Statistical Program for the Social Sciences (SPSS) was used to analyze data. Model-data fit was judged according to the contribution of each variable block for explaining mathematics achievement scores, based on a statistically significant improvement in $R^{2}$. R-Squared is the proportion of variance in the dependent variable, which can be explained by the independent variables. Using prior research on professional development (Starman et al., 2014; Yoon et al., 2006) as a guide, a criteria level of $60 \%$ of the total variance in K-PREP mathematics Part A test performance would be explained by the total of independent variables was established. To determine if each Block of the Hierarchical Linear Multiple Regression added statistical improvement to explaining the Dependent Variable of student achievement, the researcher looked at the change in $R^{2}$, as well as the $p$ value of each Block. Specifically the significance of change 
in $R^{2}$ was determined by reviewing the $F$ statistic and the $p$ value for each Block. If the Block was statistically significant, having a $p$ value less than 0.05 , the researcher reviewed each independent variable to determine if the $p$ value of each variable was less than 0.05 and therefore statistically significant on it's own. Multicollinearity was determined based on a variance of inflation factor (VIF; Field, 2005) statistic above seven, which indicates the variance of each individual regression coefficient when there is no correlation among predictor variables. When $R^{2}$ is computed in SPSS, the tolerance value is an indication of the percent of variance in the predictor that cannot be accounted for by the other predictors, so that very small values indicated overlap or sharing of predictive power (Ho, 2013). According to Robert Ho (2013), power values that are less than 0.10 may merit further investigation. Student Achievement scores from Part A of the K-PREP Math assessment, for 2013-2014 and 2014-2015, were recorded using the raw score which is an interval score ranging from 1-99. Teacher participation was recorded as two separate indicators, Full Participation $($ Full $=1$, Not Fully Participating $=$ 0) and Partial Participation (Partial $=1$, Not Partial Participation). 
Table 1

Measurement of Variables

\begin{tabular}{lll} 
Independent Variables & Measured: & Level of Measurement \\
\hline & $0-$ not eligible & \\
Free Lunch Eligibility & $1-$ eligible & nominal \\
& $0-$ not eligible & \\
Reduced Lunch Eligibility & $1-$ eligible & nominal \\
& $0-$ not eligible & \\
LEP Eligibility & $1-$ eligible & nominal \\
& $0-$ not eligible & \\
ECE Eligibility & $1-$ eligible & nominal \\
& Raw Score & interval \\
Prior Year Test Scores & $0-$ not eligible & \\
Full Participation in Professional & $1-$ eligible & nominal \\
Development & & \\
Partial Participation in Professional & $0-$ not eligible & \\
Development & $1-$ eligible & nominal \\
\hline
\end{tabular}

Dependent Variable

K-PREP Math Assessment Raw Score interval

Note. LEP = Limited English Proficiency, ECE = Exceptional Childhood Education

Research question 2 served to provide additional information from the participants on the extent the professional development provided changed their ongoing instructional practices in the classrooms and how the participants felt the quality of the professional development adequately prepared them for the curricular demands of the $21^{\text {st }}$ Century classroom. The survey questions pertaining to instructional practice contained six questions and used a five-point Likert scale which included the following options starting with one: Not at all prepared, A little prepared, Somewhat prepared, Fairly well prepared, Very well prepared. The researcher analyzed survey responses using descriptive statistics. The mean values of survey questions relating to the long-term 
influence of reform style professional development on instructional practice will be used to determine any long-term significance of this professional development model. For example, if a the mean score of a question fell in the range of 4.0-5.0, the teachers feel fairly well prepared to very well prepared to implement the instructional practiced introduced in the professional development in their classrooms. This survey was distributed 8 months following the last professional development date, requiring teachers to reflect back prior to responding to the survey questions. Due to the limited response rate for teachers participating in the professional development, only eight responded, the researcher reported these findings, but can draw no statistical conclusions for the data that would be scalable to the group as a whole. 


\section{CHAPTER 4}

\section{RESULTS}

This chapter reports study findings of the results of the data analysis explained in Chapter 3. The purpose of this study was to determine if teacher participation in reform style professional development, controlling for student demographic variables and prior student test scores, contributed to a significant increase in student achievement on the 2015 fifth grade math K-PREP test. This chapter reports the findings related to the relationship of the student-level independent variables, ECE eligibility, LEP eligibility, free lunch eligibility, reduced lunch eligibility, prior year test scores, and the teacher level independent variable of participation in professional development, with the dependent variable of student achievement.

\section{Research Questions}

Research Question 1: Is reform style professional development positively associated with students' mathematics achievement?

Independent Variables: ECE eligibility, LEP eligibility, free lunch eligibility, reduced lunch eligibility, prior year student test scores, and teacher participation in professional development (fully, partially, none).

Dependent Variable: K-PREP Part A raw score for 2014-2015 
Research Question 2: What are teacher's perceptions of reform style professional development's effectiveness on their instructional practices and student achievement?

\section{Participants and Descriptive Statistics}

The researcher collected data according to the plan outlined in Chapter 3. This study included data for all students who competed Math Part A of the 2015 K-PREP state assessment during their fifth grade year. Specifically, the study sample consisted of 6,142 students across 258 classrooms, in 87 schools within JCPS who completed the math portion of the fifth grade K-PREP assessment in the spring of 2015. Three elementary schools were omitted from the study, as the JCPS research department could not separate test data by teacher. Students who did not complete the K-PREP assessment in the spring of 2015, but were enrolled in JCPS during that time, were omitted from this study due to lack of assessment data. There were 146, fifth grade students, who did not complete the math portion of the K-PREP assessment and were therefore omitted. The researcher does not know the logic behind the missing K-PREP scores.

Students participating in this study were enrolled in fifth grade during the 20142015 school year and completed the K-PREP test for mathematics. Of the 6,142 students who completed Part A of this assessment, 635 students were eligible for ECE services while 5,507 students did not receive ECE services. Only 260 students received Limited English Proficiency (LEP) services during the 2014-2015 school year, while 5,882 students did not receive LEP services. The majority of the students taking the K-PREP assessment in fifth grade during the 2014-2015 school year, 3,844 students, received free lunch, 335 received reduced lunch, and the remaining 1,963 were paid lunch. Descriptive statistics for the student participants appear in Table 2. This table contains information 
regarding socio-economic status, Limited English Proficiency (LEP) eligibility, and Exceptional Childhood Education (ECE) eligibility.

Table 2

Student Demographic Variables

\begin{tabular}{|c|c|c|c|c|}
\hline Independent Variables & $\begin{array}{c}\text { Sample } \\
\text { Frequency }\end{array}$ & $\begin{array}{c}\text { Average } K \text {-PREP } \\
\text { Math Score } \\
\end{array}$ & $S D$ & $\begin{array}{c}\text { JCPS } \\
\text { Frequency }\end{array}$ \\
\hline $\begin{array}{l}\text { ECE eligibility for 2014- } \\
2015\end{array}$ & $10.30 \%$ & 30.91 & 25.61 & $12.50 \%$ \\
\hline $\begin{array}{l}\text { LEP eligibility for } 2014- \\
2015\end{array}$ & $4.20 \%$ & 33.44 & 21.52 & $5.20 \%$ \\
\hline $\begin{array}{l}\text { Free Lunch eligibility for } \\
\text { 2014-2015 }\end{array}$ & $62.60 \%$ & 43.37 & 26.42 & $61.25 \%$ \\
\hline $\begin{array}{l}\text { Reduced Lunch eligibility } \\
\text { for } 2014-2015\end{array}$ & $5.50 \%$ & 53.64 & 27.67 & $6.25 \%$ \\
\hline $\begin{array}{l}\text { Note. } N=5,899 \\
\text { LEP = Limited English Proficie } \\
\text { Education; SD = Standard Devi } \\
\text { Rating for Education Progress }\end{array}$ & $\begin{array}{l}\text { CE }=\text { Except } \\
\text { K-PREP = K }\end{array}$ & $\begin{array}{l}\text { Childhood } \\
\text { ky Performance }\end{array}$ & & \\
\hline
\end{tabular}

Using JCPS PD Central data to determine professional development attendance, 10 fifth grade teachers attended two, three, or four reform style professional development sessions, 16 fifth grade teachers attended one reform style professional development session, and 199 teachers did not attend any of the reform style professional development sessions. There were a total of 225 teachers reporting student achievement data in this study. For the purpose of this study teachers were divided into three groups, full participation if they attended two or more full day sessions, partial participation if they attended one full day session and did not participate if they did not attend any sessions.

\section{Null and Alternate Hypotheses}

The hypotheses for the hierarchical linear multiple regression model were: 
$\mathrm{H}_{0}: \mathrm{R}=0$, or, the multiple correlation coefficient, $R$, was zero; i.e., in the 20142015 school year, there was no significant relationship between students' mathematics achievement and a linear combination of the predictor variables; and

$\mathrm{H}_{\mathrm{a}}: \mathrm{R} \neq 0$, i.e., a significant relationship exists between students' mathematics achievement and a linear combination of the predictor variables.

The null hypothesis, $\mathrm{H}_{\mathrm{o}}$, regarding statistical significance of reduced lunch eligibility, free lunch eligibility, LEP eligibility, ECE eligibility, prior year test scores, full participation in professional development, and partial participation in professional development were rejected, as these variables contributed significantly to the prediction of fifth grade math K-PREP scores (regression coefficients, standard errors and significance statistics can be found in Table 7). With respect to the assumption of no multicollinearity (i.e., that two or more variables are not very closely linearly related), (a) correlation between any two predictors (see Table 6) was less than .8 (field, 2005), (b) the largest variance inflation factor (See VIFs in Table 7) was well below 10 (Field, 2005), and (c) tolerance values (see Table 7) were well above .1 (Field, 2005). Multicollinearity was not a problem. Specks on the VIF indicate all were less than 1.5, indicating multicollinearity was not an issue.

The mean raw score for the fifth graders during the 2014-2015 school year, KPREP Part A mathematics test was $51.68(\mathrm{SD}=28.60)$. The range of scores extended from one to 99, with 187 students received a 99, the highest score recorded and 39 students received a one, or the lowest score recorded. Of the 5,899 students involved in this study, $10.3 \%$ of the students, or 635 students were eligible for ECE accommodations, $4.2 \%$ of students, or 260 , were eligible for LEP accommodations, $62.6 \%$ or 3,844 
qualified for free lunch, and $5.5 \%$ or 335 students qualified for reduced lunch during the 2014-2015 school year. Average achievement scores for students in classrooms were teachers did not participate were $49.28(\mathrm{SD}=28.27)$, student scores for teachers partially participating were $59.54(\mathrm{SD}=28.03)$, and student scores for teachers fully participating were $63.95(\mathrm{SD}=27.40)$. These descriptive statistics can be found below in Table 3. Of the 225 teachers in the study sample, 10 teachers which accounted for 596 student test scores, fully participated in the professional development, 16 teachers, which accounted for 584 student test scores, partially participated in the professional development and the remaining 199 teachers, which accounted for 4,962 student test scores, did not participate in the professional development at all. 
Table 3

Descriptive Statistics

\begin{tabular}{lccc}
\hline & Mean & $S D$ & Frequency \\
\hline K-PREP Score 2014-2015 (DV) & 51.68 & 28.60 & \\
ECE eligibility for 2014-2015 & & & $10.30 \%$ \\
LEP eligibility for 2014-2015 & & $4.20 \%$ \\
Free Lunch eligibility for 2014-2015 & & $62.60 \%$ \\
Reduced Lunch eligibility for 2014-2015 & & & $5.50 \%$ \\
$\begin{array}{l}\text { Prior K-PREP Test Score for 2013-2014 } \\
\text { Fully Participated in Professional }\end{array}$ & 53.89 & 27.81 & \\
$\begin{array}{l}\text { Development } \\
\text { Partially Participated in Professional }\end{array}$ & 63.95 & 27.40 & $9.70 \%$ \\
$\begin{array}{l}\text { Development } \\
\text { Did not Participate in Professional } \\
\text { Development }\end{array}$ & 59.54 & 28.03 & $9.50 \%$ \\
\hline
\end{tabular}

Note. $N=5,899$ (students) $;=225$ (teachers)

$\mathrm{K}-\mathrm{PREP}=$ Kentucky Performance Rating for Education Progress; SD = Standard Deviation minimum score for K-PREP = 1; maximum score for K-PREP = 99

Student achievement scores for 2014-2015 were $54.07(\mathrm{SD}=27.96)$ for student not eligible for ECE services, and 30.91 ( $\mathrm{SD}=25.606)$ for student eligible for ECE services. Student achievement scores for 2014-2015 were $65.57(\mathrm{SD}=26.66)$ for student not eligible for free lunch, and 43.37 ( $\mathrm{SD}=26.42)$ for student eligible for free lunch. Students eligible for reduced lunch scored an average of $53.64(\mathrm{SD}=27.66)$ and student not eligible for reduced lunch scored $51.56(\mathrm{SD}=28.66)$. Students eligible for reduced lunch are the only sub group of students reported who out performed the student ineligible for the service provided. The breakdown of student scores by teacher sub groups can be found in Table 4 . 
Table 4

Descriptive Statistics for Teacher Groups

\begin{tabular}{lcccc}
\hline & $\begin{array}{c}\text { Mean for } \\
\text { 2013-2014 K- } \\
\text { PREP Scores }\end{array}$ & $\begin{array}{c}\text { SD for 2013- } \\
\text { 2014 K-PREP } \\
\text { Scores }\end{array}$ & $\begin{array}{c}\text { Mean for } \\
\text { 2014-2015 K- } \\
\text { PREP Scores }\end{array}$ & $\begin{array}{c}\text { SD for 2014- } \\
\text { Scores }\end{array}$ \\
\hline $\begin{array}{l}\text { Fully Participated in } \\
\text { Professional } \\
\text { Development } \\
\begin{array}{l}\text { Partially Participated } \\
\text { in Professional }\end{array}\end{array}$ & 64.84 & 25.42 & 63.95 & 27.40 \\
$\begin{array}{l}\text { Development } \\
\text { Did not Participate } \\
\text { in Professional } \\
\text { Development }\end{array}$ & 58.70 & 26.69 & 59.54 & 28.03 \\
\hline
\end{tabular}

Note. $N=5,899$ (students) $;=225$ (teachers)

K-PREP $=$ Kentucky Performance Rating for Education Progress; SD = Standard Deviation

minimum score for K-PREP = 1; maximum score for K-PREP $=99$

\section{Research Question 1}

To address Research Question 1, IBM SPSS Statistics software (version 22) was used to conduct a hierarchical linear multiple regression between fifth grade K-PREP Part A math scores as the criterion variable and student characteristics, prior test scores, and teacher participation as three blocks of predictor variables to determine significant increases $(p<0.05)$ in student mathematics achievement for the 2014-2015 school year. The first block of Independent Variables were ECE eligibility for 2014-2015, LEP eligibility for 2014-2015, free lunch eligibility for 2014-2015, and reduced lunch eligibility for 2014-2015. Each of the Independent Variables was dummy coded where 0 means 'not eligible' and 1 means 'eligible.' The second block of Independent Variables were the students' prior year math Part A test scores for the 2013-2014 school year. The third block of Independent Variables were fully participated in reform style professional 
development, and partially participated in reform style professional development. These variables were dummy coded for partial participation: for 'participated fully' and 0 for 'not participating' or 'participated partially'. Fully participating was coded as follows: 1 for 'participated partially' and a 0 for 'not participating' or 'participated fully'. Table 4 reports the results for the variables incorporated into the hierarchical linear multiple regression model.

Block 1 included the student predictors and the model was significant $F(4,5894)$ $=384.625, p<.001$ and a $R^{2}$ of .21 . This model only includes student-level predictors, without prior year test scores. Each of the predictors in this model was statistically significant (highest to lowest, as the unstandardized coefficients in parentheses show): free lunch eligibility $(\beta=-22.78, p<.001)$, ECE eligibility $(\beta=-19.42, p<.001)$, reduced lunch eligibility $(\beta=-12.90, p<.001)$, and LEP eligibility $(\beta=-12.01, p<.001)$. Students coded as zero were not eligible for these services, indicating student not eligible for free lunch, ECE, reduced lunch. or LEP had higher math achievement scores. Each of the four student characteristics entered into this model have a significant negative influence on their math achievement score, with the highest negative influence coming from free lunch eligibility.

Block 2 of the sequence was a model in which the above student-level predictors are included with the addition of prior year test scores, this model was statistically significant $F(1,5893)=1910.140, p<.001$, and resulted in a .41 change in $R^{2}$. The addition of prior year test scores increased the predictability of the model by $41 \%$, indicating this predictor alone predicts the majority of the overall model. With the addition of such a strong predictor, LEP eligibility was no longer statistically significant. 
Each of the predictors in the model rank as follows (highest to lowest, as the unstandardized coefficients in parentheses show): free lunch eligibility $(\beta=-7.67, p<$ $.001)$, reduced lunch eligibility $(\beta=-4.56, p<.001)$, ECE eligibility $(\beta=-2.60, p<.001)$, prior year test scores $(\beta=.74, p<.001)$, and LEP eligibility $(\beta=-.33, p>.05)$. Free lunch and reduced lunch eligibility remain the strongest negative predictors in the model, indicating students who do not receive these services score better on mathematics achievement tests.

Block 3 of the sequence takes into account all student-level predictors in addition to teacher-level predictors of partial participation in professional development and full participation in professional development for a total of seven predictor variables for mathematic achievement. This model was statistically significant $F(2,5891)=1375.11, p$ $<.001$, but only resulted in a small change in $R^{2}$ of .002 . While still statistically significant in block two, this is only a change of $2 \%$ for an overall prediction of $62 \%$. This regression model indicates the most significant of the seven-predictor variables was the negative student-level predictor of free lunch eligibility, followed by the negative predictor of reduced lunch eligibility. The strongest teacher-level predictor of mathematics achievement was partial participation in reform style professional development. All predictor variables were significant in Block 3 except for LEP eligibility, the results are as follows: free lunch eligibility $(\beta=-7.27, p<.001)$, reduced lunch eligibility $(\beta=-4.23, p<.001)$, partial participation in reform style professional development $(\beta=4.18, p<.001)$, ECE eligibility $(\beta=-2.54, p<.001)$, full participation in reform style professional development $(\beta=1.74, p<.05)$, prior test score $(\beta=.74, p<$ 
$.001)$, and LEP eligibility $(\beta=-.29, p>.05)$. Table 4 reports the findings of each block of this hierarchical linear multiple regression.

Three variable blocks of predictors were used in this hierarchical linear multiple regression (a) student demographics: free lunch eligibility (Eligible $=1$ ), reduced lunch eligibility $($ Eligible = 1), LEP eligibility $($ Eligible $=1)$, and ECE eligibility $($ Eligible = 1); (b) prior year test scores; and (c) teacher participation in professional development, either partial (Partial $=1)$ or full $($ Full $=1)$ participation. Using the overall model, including all three blocks, $62 \%$ of the variance in math achievement as measured by the state mandated K-PREP assessment was attributable to the combined effect of these predictors. Each predictor was initially significant in the hierarchical linear multiple regression model, although LEP eligibility was not significant in the second or third step when combined with other variables. LEP eligibility was $(\beta=-12.10, p<.001)$ in Model 1 , then no longer significant as $(\beta=-.33, p>.05)$ in Model 2 , or $(\beta=-.29, p>.05)$ in Model 3. Student achievement scores in 2014-2015 were $52.48(\mathrm{SD}=2728.61)$ for student not eligible for LEP services, and 33.44 (SD = 21.52) for student eligible for LEP services. The ordering of the beta values associated with prior math achievement suggests that students are responsive to instruction, while free lunch eligibility and reduced lunch eligibility are the two most significant negative predictors of mathematics achievement. 
Table 5

Hierarchical Linear Multiple Regression Results

\begin{tabular}{|c|c|c|c|c|}
\hline Variable & & & & \\
\hline & $R^{2}$ & $\Delta R^{2}$ & $B$ & $S E$ \\
\hline Block 1 & .21 & $.22 *$ & & \\
\hline ECE Eligibility & & & $-19.40 *$ & 1.10 \\
\hline LEP Eligibility & & & $-12.09 *$ & 1.78 \\
\hline Free Lunch & & & $-22.78^{*}$ & .73 \\
\hline Reduced Lunch & & & $-12.90 *$ & 1.53 \\
\hline Block 2 & .62 & $.41 *$ & & \\
\hline ECE Eligibility & & & $-2.60 *$ & .79 \\
\hline LEP Eligibility & & & -.33 & 1.24 \\
\hline Free Lunch & & & $-7.67 *$ & .54 \\
\hline Reduced Lunch & & & $-4.56^{*}$ & 1.07 \\
\hline K-PREP Part A Raw Score 2013-2014 & & & $.74 *$ & .01 \\
\hline Block 3 & .62 & $.00 *$ & & \\
\hline ECE Eligibility & & & $-2.54 *$ & .79 \\
\hline LEP Eligibility & & & -.29 & 1.24 \\
\hline Free Lunch & & & $-7.27 *$ & .55 \\
\hline Reduced Lunch & & & $-4.23 *$ & 1.07 \\
\hline K-PREP Part A Raw Score 2013-2014 & & & $.74 *$ & .01 \\
\hline Fully Participated & & & $1.74 *$ & .80 \\
\hline Partially Participated & & & $4.18^{*}$ & .80 \\
\hline
\end{tabular}

Note. $* p<.05$

$R^{2}=$ measure of strength of association; $\Delta R^{2}=$ Change in $R^{2} ; B=$ unstandardized coefficients; $\mathrm{SE}=$ Standard errors; ECE = Exceptional Childhood Education; LEP = Limited English Proficiency; K-PREP = Kentucky Performance Rating for Educational Progress

minimum score for K-PREP = 1; maximum score for K-PREP $=99$

Block 1 included the student level predictors of LEP eligibility, ECE eligibility, free lunch eligibility and reduced lunch eligibility, which established $21 \%$ of the total variance for mathematics achievement scores. After controlling for the aforementioned student level factors, Block 2 also included students' prior year test score from the 20132014 K-PREP assessment, which accounted for $61.8 \%$ of the total variance. Block 3 with the inclusion of teacher participation in professional development, either partially of 
fully, was entered into the model. Block 3 accounts for a small amount increase in the variance to $62 \%$, but statistically significant. Each block in this hierarchical multiple linear regression model is statistically significant indicating the null hypothesis is rejected, as each addition to the model are related to changes in the response variable since the each $F$ change is significant, these statistics can be found below in Table 6.

Table 6 Hierarchical Linear Multiple Regression Model Summary Block

\begin{tabular}{|c|c|c|c|c|c|c|c|c|c|}
\hline & \multirow[b]{2}{*}{$R$} & \multirow[b]{2}{*}{$R^{2}$} & \multirow[b]{2}{*}{$\begin{array}{c}\text { Adjusted } \\
R^{2}\end{array}$} & \multirow[b]{2}{*}{$\begin{array}{l}\text { Std. Error } \\
\text { of the } \\
\text { Estimate }\end{array}$} & \multicolumn{5}{|c|}{ Change Statistics } \\
\hline & & & & & $\begin{array}{c}R^{2} \\
\text { Change }\end{array}$ & $\begin{array}{c}F \\
\text { Change }\end{array}$ & df1 & df2 & $\begin{array}{l}\text { Sig. } F \\
\text { Change }\end{array}$ \\
\hline 1 & $.46^{\mathrm{a}}$ & .21 & .21 & 25.49 & .21 & 384.63 & 4 & 5894 & .000 \\
\hline 2 & $.80^{\mathrm{b}}$ & .62 & .62 & 17.68 & .41 & 6353.92 & 1 & 5893 & .000 \\
\hline 3 & $.79^{c}$ & .62 & .62 & 17.64 & .002 & 14.95 & 2 & 5891 & .000 \\
\hline
\end{tabular}

a Predictors: (Constant), Reduced Lunch, LEP Eligibility for the 2014-2015 school year, ECE eligibility for the 2014-2015 school year, Free Lunch

${ }^{b}$ Predictors: (Constant), Reduced Lunch, LEP Eligibility for the 2014-2015 school year, ECE eligibility for the 2014-2015 school year, Free Lunch, KPREP Part A Raw Score 2013-2014

'Predictors: (Constant), Reduced Lunch, LEP Eligibility for the 2014-2015 school year, ECE eligibility for the 2014-2015 school year, Free Lunch, KPREP Part A Raw Score 2013-2014, Partially Participated, Fully Participated

Note. $R=$ multiple correlation; $R^{2}=$ multiple correlation squared; Adjusted $R^{2}=$ coefficient of determination; $R^{2}$ change = change in multiple correlation squared; $F$ Change = variance change between populations; df = degrees of freedom; Sig. $F$ Change - Significance of change in $p$ value

\section{Research Question 2}

Research Question 2: How do teachers perceive reform style professional development's effectiveness on student achievement and lasting influence on their instructional practices?

Teachers, who taught math, during the 2014-2015 school year, were surveyed electronically using the survey from Appendix A. Of the 258 teachers surveyed, only 46 responded to the survey, and of those 46, only 41 agreed to participate. Within the 
remaining 41 teachers who answered the survey questions, only eight teachers attended one or two of the professional development sessions. With a response rate of $20 \%$ and only eight teacher participants who completed the survey attended the professional development, the demographic data the researcher intended to use to control for teacher variables was not used. Of the 258 teachers surveyed, whose student scores are included in this study, 41 of them agreed to complete the survey located in Appendix A. Of the 41 teachers who completed the survey, only five of them partially participated in the reform style professional development, three of them fully participated in the professional development, while the remaining 33 of them did not participate at all.

The 41 teachers who responded to the survey produced the following results. The highest level of education attained by the school year 2014-2015 was: one teacher or 2\% had a Bachelor's Degree, 25 teachers or 61\% had a Master's Degree, 14 or 34\% have a Rank I (i.e. 30 hours over a Master's) and one or 2\% had a Doctoral Degree. During the 2014-2015 school year, 23 or $56.1 \%$ of teachers surveyed taught all subjects, nine or $22 \%$ departmentalized, meaning they taught math for the entire fifth grade, three or $7.3 \%$ departmentalized and taught reading, one or $2.4 \%$ departmentalized and taught writing, and five or $12.2 \%$ indicated other for their teaching arrangement on Question 4. The researcher went through student assessment data used for Research Question 1 and confirmed zero of the teachers indicating in question 4 that they taught a content area other than Math attended the reform style professional development and the student achievement data used for the purposes of this study indicated no teacher in that school attended the math professional development. 
Teachers responding to the survey taught between two and 39 years. The majority of teachers, $85 \%$ or 35 teachers, were teaching 20 years or less. 18 teachers, or $44 \%$ taught 10 years or less, five teachers, or $12 \%$ taught between 21 and 28 years, and only one teacher, or $2 \%$ taught for 39 years. Additional research could be done with a larger group of teachers to determine if years of teaching have a significant influence on student achievement in any core subject.

Teachers surveyed indicated in Question 6 how many years they have been teaching math at their current school. This data was collected to potentially determine if higher years in one location would contribute to higher achievement scores through building capacity in the building. The range of answers was one to 18 years. The majority of teachers, 20 or $49 \%$, have been teaching five years or less in their current building, 12 teachers or $29 \%$ have been there between six and 10 years, four teachers or $10 \%$ for 11 15 years and five teachers or $12 \%$ for $16-18$ years. Of the 41 teachers responding to the survey only eight teachers or $19.5 \%$ held a math certification during the 2014-2015 school year, while the majority of teachers, 33 or $80.5 \%$ did not. This was not surprising since the study was conducted using elementary teachers and certification in the content area they teach is not required to be considered highly qualified, at the elementary level, by the state of Kentucky.

Question 9 asked how many years of experience teaching math each teacher had during the 2015-2016 school year. Answers ranged from one to 28 years, 10 teachers or $24.5 \%$ taught math for five years or less, 13 or $32 \%$ taught math for $6-10$ years, four or $10 \%$ taught math for $11-15$ years, 10 or $24.5 \%$ taught math for $16-20$ years, one or $2 \%$ taught math for 21-25 years, and three or 7\% taught math for 26-28 years. The researcher 
noted of the eight teachers who completed the survey and attended the professional development, five of the eight have been teaching math for 17 to 27 years. It would be interesting to follow up with a qualitative study to determine why the majority of teachers participating in high level professional development have a significant amount of experience teaching the content area they are choosing to learn about.

\section{Table 7}

\section{Teacher Survey Frequencies}

\begin{tabular}{|c|c|c|c|c|c|}
\hline & $\begin{array}{l}\text { Not at all } \\
\text { prepared }\end{array}$ & $\begin{array}{l}\text { A little } \\
\text { prepared }\end{array}$ & $\begin{array}{l}\text { Somewhat } \\
\text { prepared }\end{array}$ & $\begin{array}{c}\text { Fairly } \\
\text { well } \\
\text { prepared }\end{array}$ & $\begin{array}{l}\text { Very well } \\
\text { prepared }\end{array}$ \\
\hline $\begin{array}{l}\text { Take a students' prior } \\
\text { understanding into account } \\
\text { when planning curriculum } \\
\text { and instruction. }\end{array}$ & & & & 4 & 4 \\
\hline $\begin{array}{l}\text { Develop students' } \\
\text { conceptual understanding } \\
\text { of mathematics. }\end{array}$ & & & & 4 & 4 \\
\hline $\begin{array}{l}\text { Make connections between } \\
\text { mathematics and other } \\
\text { disciplines. }\end{array}$ & & & 3 & 3 & 2 \\
\hline $\begin{array}{l}\text { Lead a class of students } \\
\text { using inquiry strategies. }\end{array}$ & & & & 4 & 4 \\
\hline $\begin{array}{l}\text { Routinely use and evaluate } \\
\text { formative assessment } \\
\text { lessons to gauge their } \\
\text { understanding. }\end{array}$ & & & & 4 & 4 \\
\hline $\begin{array}{l}\text { Manage a class of students } \\
\text { engaged in hands- } \\
\text { on/project-based work. }\end{array}$ & & & & 4 & 4 \\
\hline
\end{tabular}


The eight teachers who attended at least one session of reform style professional development completed the second portion of the survey that focused on long-term change to instructional practices. Five teachers attended one session of professional development and three teachers attended two sessions, no teachers, which attended three or four sessions, completed the survey. Question 13 asked teachers, via a five point Likert-scale, how prepared they feel to take students' prior understanding into account when planning curriculum and instruction. The scale ranged from not at all prepared (1), a little prepared (2), somewhat prepared (3), fairly well prepared (4) and very well prepared (5). Four teachers indicated they feel fairly well prepared and four teachers indicated they felt very well prepared. This indicates all teachers felt adequately prepared to plan for instruction while taking into account students' prior understanding. This was important, as it was a focus of the reform style professional development design. The remaining questions in this grid, develop students' conceptual understanding of mathematics, lead a class discussion of students using inquiry strategies, routinely evaluate formative assessment lessons to gauge student understanding, and manage a class of students engaged in hands-on/project-based work, indicated and equal split of four teachers for fairly well prepared, and four teachers for very well prepared. No teachers indicated anything lower than a four on the five-point Likert-scale for any question except make connections between mathematics and other disciplines. This question produced two teachers for very well prepared (5), three teachers for fairly well prepared (4) and two teachers for somewhat prepared (3). This indicated more time might need to be spent on embedding other disciplines into every professional development day. These cross curricular activities were taught in one of the four sessions for art and 
another session for music, if the teachers answering the survey attended on a different day, they would not be exposed to the instructional strategies presented in the professional development. 


\section{CHAPTER 5}

\section{DISCUSSION AND RECCOMONDATIONS}

The purpose of this study was to explore relationships among the CCSS, reform style professional development, and student achievement by comparing math achievement predictive models and considering how the results of the models might influence planning for math professional development. The study focused on two research questions: Research Question 1 addressed how hierarchical linear modeling informs the prediction of mathematics achievement from linear combinations of student characteristics and prior year test scores. Research Question 2 addressed the long-term influence of reform style professional development on classroom instructional practice, but did not have adequate survey data to draw large-scale conclusions.

This study used a hierarchical linear multiple regression to inform the prediction of mathematics achievement from a linear combination of student characteristics, ECE eligibility, LEP eligibility, free lunch eligibility, reduced lunch eligibility, prior year test scores, and teacher characteristics such as full participation in reform style professional development, partial participation in reform style professional development, or no participation in reform style professional development. Considering the time and money spent conducting professional development in JCPS, the researcher believes the validation of significant increases in student achievement promoted the continuation of this reform style professional development program. Factoring in the additional time 
required for planning professional development using researched based instructional strategies and spending time analyzing the CCSS has proven effective for this group of teachers on fifth grade math achievement.

As predicted in the research, free lunch eligibility was the strongest negative predictor for student achievement scores, followed by free lunch eligibility, both of which are well documented in the research. Partial participation in reform style professional development was the highest positive predictor in this hierarchical linear multiple regression equation. Partial participation in professional development was the third highest predictor overall, where full participation in the professional development came in after ECE eligibility. Research indicates the more teachers participate in reform style professional development, focusing on instructional practices, discussing standards, and building relationships with other math teachers their student achievement scores would continue to improve as they bring these resources back to their classrooms and change their instructional practices (Yoon et al., 2007; Wei et al., 2009; Yoon et al., 2006). The results of this study determined this was not the case. In this study, attending only one session of reform style professional development provided significantly higher results than participates who participated in two, three, or four sessions. This does not correlate with the literature suggesting reform style professional development must be ongoing to achieve results (Darling-Hammond, Wei, Andree, Richardson, \& Orphanos, 2009; Garet et al., 2001).

The student demographic variables collected for this study, all contributed negatively to student achievement in math. The most significant were free lunch eligibility, followed by reduced lunch eligibility, ECE eligibility and LEP eligibility. 
These findings are consistent with previous studies (Guskey, 2009; Killen \& Hattingh, 2004; McCarthy, 2012). Additional research may seek to determine if reform style professional development produced any change in the achievement gap for these sub groups of students. It would be interesting to investigate if reform style professional development could lower the achievement gap for any reported sub groups of students, and potentially add additional sub groups to the analysis.

The tested hypothesis, if reform style professional development has a positive and significant relationship with student achievement was confirmed. Students in classrooms where teachers partially participated in the reform style professional development had a greater positive relationship on mathematics achievement than students whose teacher participated fully which goes against previous research indicating to be effective professional development must be sustained (Yoon et al., 2007; Wei et al., 2009; Yoon et al., 2006). Further research may want to investigate the logic behind these differences. Potentially guiding a teacher in the direction of researched based teaching practices and focusing on CCSS is enough when that teacher has the intrinsic motivation to increase student achievement. In this study teachers who attended partially produced a higher positive relationship with their students' mathematics achievement, if this could be replicated another year with the same results, the school district could potentially decrease the number of days teachers are invited to participate. This could either save district funds or offer the opportunity to more teachers in the district to participate, therefore potentially increasing student mathematics achievement in additional classrooms. Another research possibility would be to conduct this study again using the 
criterion-referenced portion of the K-PREP assessment to determine if the results were similar.

Teachers responding to the survey produced results aligned with the assumption of the researcher for educational attainment. Kentucky requires teachers to gain a Master's Degree before their fifth year of teaching or they lose their Kentucky teaching license (Kentucky Department of Education, 2014). As a result, 95\% of teachers surveyed already obtained their masters degree and another $34 \%$ have 30 credit hours over their Master's in a program Kentucky calls Rank I. Teacher in the state of Kentucky typically have more advanced degrees than other states who do not require teachers to obtain a Master's Degree so early in their teaching career (Butrymowicz, 2015). It was surprising that one of the teachers surveyed had a Doctoral Degree and had been teaching 39 years. All teachers surveyed taught fifth grade during the 2014-2015 school year and per the norm in JCPS, 23 of them, or $56.1 \%$ taught all subjects. Many elementary schools in JCPS do not departmentalize instruction due to the time constraints on teachers to fit all core subjects into the school day. Fifth grade, eighth grade, and $10^{\text {th }}$ grade are the highest tested grade levels in the state of Kentucky, these students are assessed in Reading, Mathematics, Social Studies, Science, and Writing (Kentucky Department of Education, 2014).

Teachers included in this study taught between two and 39 years, the majority of the teachers taught 20 years or less. In the state of Kentucky teachers can retire after 27 years of service (Kentucky Department of Education, 2014). It would be interesting to have a larger sample size to determine if years of experience made a significant influence on student achievement (Starman et al., 2014). Kentucky adopted the CCSS in 2011, so 
any teacher teaching three years or more at the time of this study were involved with these standards from the start. It would be interesting to gain insight from teachers teaching 20 years or more, how the standards have changed from Core Content for Assessment standards to CCSS. It would be an additional factor to note if years of teaching math made a significant difference in student achievement, which is a more significant predictor of student math achievement, years of teaching overall or years of teaching math (Murphy \& Torff, 2014).

Only eight teachers who completed the survey attended at least one session of reform style professional development. The researcher noted that among these eight teachers, all answered they felt fairly well prepared or very well prepared to each instructional practice question. This suggests that the respondents perceived the instructional value in the reform style professional development stuck with the participants eight months after the last professional development session was offered. Teachers leaving these professional development sessions felt adequately prepared to plan for instruction while taking into account student's prior understanding, develop students' conceptual understanding of mathematics, lead a class discussion of students using inquiry strategies, routinely evaluate formative assessment lessons to gauge student understanding, and manage a class of students engaged in hands-on/project-based work. Teachers attending these professional development sessions are feeling confident in their classrooms using high quality instructional practices, which are showing in the significant improvement in student achievement. This research provided validation for the math department in JCPS who plans and implements these professional development sessions. 
In research conducted prior to this study, most analysis is not significant for student achievement gains after controlling for prior year tests scores and socio economic level.

Given the importance of math education in the U.S., the societal demand for education accountability, and the emphasis on data-driven decision making, education stakeholders will benefit from the use of statistical models that are as accurate as possible and that reduce the potential of errors. Given the recent and consistent desire to provide more rigorous standards to keep our students competitive in the global job market, it is important to use statistical models that account for student characteristics at the point a student enters a school or classroom and that provide conservative estimates with respect to the statistical significance of variables that influence academic achievement. It is also important to use the statistical models that are theoretically sound for the particular structure of the data that is being modeled.

Prior math performance at the individual student level is a positive and significant predictor of math achievement in the model and at each level it was included. This adds to the body of literature that indicates that prior math knowledge significantly contributes to mathematics achievement (Dorio, 2006; Gellert, 2013; Grady, Watkins \& Montalvo, 2012; Killen \& Hattingh, 2004). This relationship between prior math performance and math achievement implies mathematics is a discipline in which new skills are built upon previous skills: e.g., a student will likely not be successful in solving an equation for $\mathrm{x}$ before the student is able to add, subtract, multiply or divide. The relationship between prior math knowledge and math achievement revealed in the literature and in this study emphasizes the following with respect to K-12 curricular policy and practice in mathematics education (Dorio, 2006; Killen \& Hattingh, 2004). Math knowledge and 
skills gained in early years of education influence students' future success in math. Therefore, it is critical that effective mathematics education begin in kindergarten for students who are school ready and in pre-school education for students who are not school ready. As funding and resource allocation decisions for math education are made at federal, state, and local levels and by philanthropic institutions, serious consideration should be given to fund programs and practices that ensure effective professional development

A growing body of research on effective professional development models for teachers provides support for a new paradigm of teacher professional learning. It should be based on evidence about the types of experiences that appear to build teacher capacity and catalyze transformations in teaching practice resulting in improved student outcomes (Darling-Hammond, et al., 2009). The United States has made some progress towards a common set of standards that are rigorous and research based, but still struggles to provide effective professional development with an increased emphasis on building teachers' content knowledge. The structures and supports which are needed to sustain teacher learning and change and to foster job-embedded professional development in collegial environments falls short (Darling-Hammond, et al., 2009).

The low ratings of the usefulness of most professional development activities indicated in the research are indicators of the insufficiency of the professional development infrastructure now in place in most states and communities (Starman et al., 2014; Yoon et al., 2006). Effective professional development targets classroom instruction and is research-based in terms of both content and pedagogy. Successful professional learning immerses teachers in the content they teach and provides research- 
based knowledge about how students learn. This study illustrates effective, CCSS focused; research-based, reform style professional development has a significant positive relationship with student mathematics achievement.

\section{Study Conclusion}

This quantitative study focusing on CCSS in conjunction with high-quality, reform style professional development looked at five student-level predictors and two teacher-level predictors to find a statistically significant, positive relationship with students' mathematics achievement. This is significant as JCPS spent approsimately $\$ 657,131$ on professional development during the 2014-2015 school year, not including substitute teacher costs. If this money can be focused on high-quality professional development, which shows a positive significant change in student achievement, it can include more teachers and students to potentially raise student achievement on a broader scope.

These findings lead to two further questions: How can states, districts, and schools build their capacity to provide high-quality professional development that is effective in building teacher knowledge, improving their instruction, and supporting student learning? And how can they assess the influence of their efforts over time?

Additional research may want to be conducted in other school districts that have implemented CCSS and reform style professional development. This would determine if student achievement in JCPS was similar to others throughout the Southeast or even across the United States. These studies could validate the findings of the current study. Comparing student achievement as a result of the reform style professional development 
to student achievement scores within multiple districts would allow each district to determine the overall effectiveness of their professional development. 


\section{REFERENCES}

American Diploma Project. (2008, January 1). American diploma project assessment consortium brochure. Retrieved from http://www .achieve.org/files/ADPAssessmentConsortiumBrochure.pdf

Anderson, G. L., \& Herr, K. (2011). Scaling up “evidence-based” practices for teachers is a profitable but discredited paradigm. Educational Researcher, 40(6), 287-289.

Birman, B., Le Floch, K. C., Klekotka, A., Ludwig, M., Taylor, J., Walters, K. (2007). State and local implementation of the No Child Left Behind Act: Vol. 2. Teacher quality under NCLB: Interim report. Washington, DC: U.S. Department of Education; Office of Planning, Evaluation.

Bostic, J., \& Matney, G. (2013). Overcoming a common storm: Designing professional development for teachers implementing the common core. Ohio Journal of School Mathematics, 12(19).

Butrymowicz, S. (2013). What Kentucky can teach the rest of the U.S. about the common core. The Atlantic. Retrieved from http://www .theatlantic.com/education/archive/2013/10/what-kentucky-can-teachthe-rest-of-the-us-about-the-common-core/280453/ 
Carpenter, T. P., Fennema, E., Peterson, P. L., Chiang, C. P., \& Loef, M. (1989). Using knowledge of children's mathematics thinking in classroom teaching: An experimental study. American Educational Research Journal, 26(4), 499-531.

Cohen, D. K., \& Hill, H. C. (2001). Learning policy. New Haven, CT: Yale University Press.

Cohen, D., \& Moffitt, S. (2009). The ordeal of equality: Did federal regulation fix the schools? Cambridge, MA: Harvard University Press.

Common Core Standards Implementation Can Lead to Improved Student Achievement. (2012, January 1). Retrieved from http://www .achieve.org/common-core-mathstandards-implementation-can-lead-improved-student-achievement

Common Core State Standards Initiative. (2010). The standards. Washington, DC:

National Governors' Association Center for Best Practices, Council of Chief State School Officers. Retrieved from www.corestandards.org

Common Core State Standards Initiative. (n.d.). Standards in your state. Retrieved from Www.corestandards.org/standards-in-your-state

Confer C., \& Ramirez, M. (2012). Small steps, big changes. Portland, ME: Stenhouse Publishers.

Conley, D. D. (2014). The common core state standards: Insight into their development and purpose. Retrieved from http://www .ccsso.org/Documents/2014/CCSS_Insight_Into_Development_2014.p df

Corcoran, T.B. (1995). Transforming professional development for teachers: A guide for 
state policy makers. Washington, DC: National Governors' Association

Crawford, J. (2011). Frequently asked questions about reauthorization of the Elementary and Secondary Education Act (ESEA) and the policy issues at stake. DiversityLearningK12. Retrieved from http://www.diversitylearningk12.com/articles/Crawford_ESEA_FAQ.pdf Creswell, J. (2005). Educational research: Planning, conducting, and evaluating quantitative and qualitative research. New Jersey: Pearson.

Darling-Hammond, L., \& McLaughlin, M. W. (1995). Policies that support professional development in an era of reform. Phi Delta Kappan, 76(8), 597-604. doi:10.1177/003172171109200622

Darling-Hammond, L., \& Richardson, N. (2009). Professional learning in the learning profession. Retrieved from www.nsdc.org/presentation

Darling-Hammond, L., Wei, R. C., Andree, A., Richardson, N., \& Orphanos, S. (2009). Professional learning in the learning profession: A status report on teacher development in the United States and abroad. National Staff Development Council.

Desimone, L. M., Porter, A. C., Garet, M. S., Yoon, K. S., \& Birman, B. F. (2002). Effects of professional development on teacher's instruction: Results from a three-year longitudinal study. Educational Evaluation and Policy Analysis, 24(2), $81-112$

Dever, R. \& Lash, M. (2013). Using common planning time to foster professional learning. Middle School Journal, 45(1), 12-17. 
Diaz-Maggioli, G. (2004). Teacher-centered professional development. Alexandria, VA: ASCD.

Dillman, D. (2007). Mail and internet surveys: The tailored design method. Hoboken, NJ: Wiley \& Sons.

Dorio, W. D. (2006). High schools good...and bad. District Administration, 42(10), 4447.

Dover, T.F. (2004). A case study of teachers' perspectives on the impact of transient students in a highly mobile elementary school. (Doctoral Dissertation).

Esqueda, D.L. (2008). Exploring teacher attributes and school characteristics as predictors of cognitively guided instruction implementation. (Doctoral Dissertation). Retrieved from http://search.proquest.com/docview/304812765

Explorable (2009). Non-Probability Sampling.

Fancella, P. J. (2010). The impact of cognitively guided instruction (A professional development program) on attitudes and beliefs toward mathematics. (Doctoral Dissertation).

Field, A. (2005). Discovering statistics using SPSS (2nd ed.). London: SAGE Publications Ltd.

Garet, M. S., Porter, A. C., Desimone, L., Birman, B. F., Yoon, K. S. (2001). What makes professional development effective? Results from a national sample of teachers. American Educational Research Journal, 38(4), 915-945.

Gay, L. R., \& Airasian, P. (2000). Educational research: Competencies for analysis and application (6th ed.). Englewood Cliffs, NJ: Prentice-Hall. 
Gellert, L. (2013). Elementary school teachers and mathematics: Communities of practice and an opportunity for change. Journal of Education and Learning, 2(4), 113122.

Gewertz, C. (2010). In national first, Kentucky adopts common standards. Education Week, 29(22), 1-13. Retrieved from http://www.edweek.org/ew/articles/2010/02/11/22kentucky_ep.h29.html

Gewertz, C. (2013). Teachers say they are unprepared for common core: Unpreparedness is cited in common-core survey. Education Week.

Grady, M., Watkins, S., Montalvo, G. (2012). Effect of constructivist mathematics on achievement in rural schools. Rural Education, 33(3), 38-49.

Guskey, T. (2000). Evaluating professional development. Thousand Oaks, California: Corwin Press.

Guskey, T. (2002). Professional development and teacher change. Teachers and Teaching, 8(3), 381-391. doi:10.1080/135406002100000512

Hirsh, S. (2006). NSDC standards provide a richer definition of professional development than does NCLB. Retrieved from http://www.nsdc.org/news/jsd/hirsh273.pdf

Hirsh, S. (2009). NSDC opens the door to professional learning that ensures great teaching for every student everyday: A new definition. Retrieved from http://www.nsdc.org/themes

Ho, R. (2013). Handbook of univariate and multivariate data analysis with IBM SPSS. CRC Press. 
Holmes, V., (2012). Depth of teachers' knowledge: Framework for teachers' knowledge of mathematics. Journal of STEM education: Innovations and research, 13(1), $55-71$

Innes, R. G. (2006). K-PREP Data Sourcebook. Bluegrass Institute for Public Policy Solutions. Retrieved from https://www.heartland.org/sites/default/files/kprep_data_sourcebook.pdf

Johnson, B. (2001). Toward a New Classification of Nonexperimental Quantitative Research. Educational Researcher, 30(2), 3-13.

JCPS at a Glance. (n.d.). Retrieved from http://www.jefferson.k12.ky.us/About/About.html

JCPS Transparency Site. (2015) Retrieved from http://openbooks.tylertech.com/jcps/TransWebPages/Home.aspx Jefferson County Public Schools. (2011). Jefferson county public schools facts 2011. Retrieved from http://www.jefferson.kyschools.us/Pubs/Facts_Booklet.pdf. Kennedy, M. (1998). Form and substance of in-service teacher education (Research Monograph No. 13). Madison: University of Wisconsin Madison, National Institute for Science Education.

Kentucky Department of Education. (2014, June 10). Retrieved from http://education.ky.gov/curriculum/ciits/pages/default.aspx

Kentucky Department of Education. (2014, November 3). Retrieved from http://education.ky.gov/AA/Assessments/Pages/K-PREP.aspx

Kentucky Senate Bill 1 -09RS SB1. (2009). Retrieved from http://www.lrc.ky.gov/record/09RS/SB1.htm 
Killen, R., \& Hattingh, S. (2004). A theoretical framework for measuring the quality of student learning in outcomes-based education. South African Journal of Higher Education. 18(1), 38-45.

King, J. E. State Higher Education Executive Officers, (2011). Implementing the common core state standards: An action agenda for higher education. District of Columbia; United States: State Higher Education Executive Officers. Retrieved from http://www.acenet.edu/news-room/Documents/Implementing-the-CommonCore-State-Standards-2011.pdf

Kornhaber, M., Griffith, K., \& Tyler, A. (2014). It's not education by zip code anymore but what is it? Conceptions of equity under the Common Core. Education Policy Analysis Archives, 22(4).

Larson, M. R. (2012). Will CCSSM matter in 10 years?: Reflect and discuss. Teaching Children Mathematics. 19(2). 108-115.

Manna, P., \& Ryan, L. (2011). Competitive grants and educational federalism: President Obama's race to the top program in theory and practice. Pubulis: The Journal of Federalism, 41(3). doi:10.1093/publius/pjr021

Mathis, William J. (2010). The common core standards initiative: An effective reform tool? Boulder, CO, and Tempe, AZ: Education and the Public Interest Center \& Education Policy Research Unit.

McCarthy, B. (2012). The learning cycle: The 21st century and millennial learners. Wauconda, IL: About Learning. 
McDonnell, L. M., \& Weatherford, M. S. (2013). Evidence use and the Common Core State Standards movement: From problem definition to policy adoption. American Journal Of Education, 120(1), 1-25. Doi:10.1086/673163

McGuinn, P. (2011). Stimulating reform: Race to the Top, competitive grants and the Obama education agenda. Educational Policy, 26(1), 136-159. doi10.1177/0895904811425911

Mertens, D. M., \& McLaughlin, J. A. (2004). Research and evaluation methods in special education. Thousand Oaks, CA: Corwin Press.

Michalec, P. (2013). Common core and inner core: Co-collaborators in teacher preparation. Curriculum and Teaching Dialogue, 15(1), 27-36.

Murphy, A. F., \& Torff, M. B. (2014). Standards and accountability in conflict: Impact of educational reforms. Delta Kappa Gamma Bulletin, 80(4). 19-21.

National Center for Education Statistics (2013). The Nation's Report Card: Trends in Academic Progress 2012. Washington DC: National Center for Education Statistics, Institute of Education Sciences, U.S. Department of Education. National Commission on Excellence in Education. (1983). A nation at risk: The imperative for educational reform. United States Department of Education: Washington, DC.

National Commission on Teaching \& America's Future. (1996). What Matters Most: Teaching for America's Future. New York: Author.

National Council of Teachers of Mathematics (2014). Illuminations. Retrieved from www.illuminations.org 
National Defense Education Act (NDEA). (2015). Encyclopedia Britannica. Retrieved from http://www.britannica.com/topic/National-Defense-Education-Act

National Governors Association Center for Best Practices \& Council of Chief State School Officers. (2010). Common Core Standards. National Governors Association Center for Best Practices \& Council of Chief State School Officers. Washington, DC: Author

National Institute for Excellence in Teaching (NIET: 2012). Beyond job-embedded: Ensuring that good professional development gets results. Santa Monica, CA: NIET.

New York State Education Department. (2009). Federal education policy and the states, a brief synopsis. Retrieved from http://www.archives.nysed.gov/edpolicy/research/res_essay_contents.shtml

No Child Left Behind (NCLB) Act of 2001, 20 U.S.C.A. § 6301 et seq. (West 2003)

Preacher, K., Curran, P., \& Bauer, D. (2006). Computational tools for probing interactions in multiple linear regression, multilevel modeling, and latent curve analysis. Journal of Educational and Behavioral Statistics, 31(4), 437-448. doi:10.3102/10769986031004437

Porter, A., McMaken, J., Hwang, J., \& Yang, R. (2011). Common core standards: The new U.S. intended curriculum. Educational Researcher, 40(3), 103-116.

Program for International Student Assessment. (2012). National Center for Education Statistics. Retrieved from: http://nces.ed.gov/surveys/pisa/pisa2012/index.asp

Reeves, A. (2011). Where great teaching begins: Planning for student thinking and learning. Alexandria, VA: ASCD Publications. 
Rotman, R. (2012). A common core of readiness. Educational Leadership, 69(7), 10-15.

Singh, A., Yager, S., \& Yukaton, N. (2012). Constructivist teaching practices used by five teacher leaders for the Iowa Chautauqua professional development program. International Journal of Environmental and Science Education, 7(2), 197-216.

Snow-Renner, R., \& Lauer, P. (2005). Professional development analysis. Retrieved from http://www.mcrel. org/PDF/ProfessionalDevelopment/5051IR_Prof_dvlpmt_analysis.pdf

Standards in Your State. (n.d.). Retrieved from http://www.corestandards.org/standardsin-your-state

Starman, J., Larson, A., Proffitt, E., Guskey, T., \& Ma. (2014). A collaborative professional development approach to improving student outcomes. Revitalizing Education: Bringing the common core state standards into the classroom, 11(2). 81-86.

Stein, M. K., Smith, M. S., \& Silver, E. A. (1999). The development of professional developers: Learning to assist teachers in new settings in new ways. Harvard Educational Review, 69, 237-269.

Stephens, J. (2012). Applied Multivariate Statistics for the Social Science (5th ed.). New York, NY: Rutledge Academic.

Torff, B., \& Byrnes, K. (2011). Differences among academic subjects in teachers' attitudes about professional development. The Educational Forum, 75(1), 105115. doi: $10.1080 / 00131725.2010 .528553$

Tyack, D., \& Cuban, L. (1995). Tinkering Toward Utopia: A Century of Public School Reform. Cambridge, MA: Harvard University Press. 
Tyminiski, A. (2009). Teacher lust: reconstructing the construct for mathematics instruction. Journal of Math Teacher Education, 13(1), 295-311.

United States Bureau of Education. (1892). Report on the committee on secondary school studies. Washington D.C.: Government Printing Office.

United States Department of Education. (2012). Overview: The federal role in education. Retrieved from http://www2.ed.gov/about/overview/fed/role.html United States Department of Education. (2013a). A Blueprint for R.E.S.P.E.C.T: Recognizing educational success, professional excellence, and collaborative teaching. Retrieved from www.ed.gov/documents/respect/blueprint United States Department of Education. (2013b). Race to the top fund. Retrieved from http://www2.ed.gov/programs/racetothetop/executive-summary.pdf

Vigdor, J. L. (2013). Solving America's math problem. Education Next: A Journal of Opinion and Research, 13(1). 42-63.

Wagner, Y. (2012). Creating innovators: The making of young people who will change the world. New York: Scribner.

Wallender (2014). The common core state standards in American public education: Historical underpinnings and justifications. Delta Kappa Gamma Bulletin, 80(4). $7-11$.

Wei, R. C., Darling-Hammond, L., Andree, A., Richardson, N., \& Orphanos, S. (2009). Professional learning in the learning profession: A status report on teacher development in the United States and abroad. National Staff Development Council. 
Weingarten, R. (2010). Statement by Randi Weingarten. American Federation of Teachers, on Common Core Standards. Retrieved from http://www.ode.state.or.us/wma/teachlearn/commoncore/ccstatementamfedteache rs.pdf

Yegidis, B., Weinbach, R. \& Morrison- Rodriguez, B. (1999). Research Methods for Social Workers (2nd ed.). Needham Heights, MA: Allyn \& Bacon.

Yoon, K. S., Duncan, T., Wen-Yu, S., Scarloss, B., Shapley, K. (2007). Reviewing evidence on how teacher professional development affects student achievement. National Center for Education Evaluation and Regional Assistance.

Yoon, K. S., Garet, M., Birman, B., Jacobson, R. (2006). Examining the effects of mathematics and science professional development on teachers' instructional practice: Using professional development activity log. Washington, DC: Council of Chief State School Officers.

Youngs, P. (2013). Using Teacher Evaluation Reform and Professional Development to Support Common Core Assessments. Washington, DC: Center for American Progress. 
APPENDIX A

Teacher E-mail and Survey

Dear Former Math.com Participants,

In an effort to complete her doctoral work with the University of Louisville, Amy Colucci is conducting a study on our math.com professional development cycles. She is in her last year of an Ed.D. program and many of you will remember her from her work with Computer Education Support. She is determining the impact math.com professional development had on student achievement during the 2014-2015 school year, and asking you to complete the linked survey below to gather additional information. Your participation in this survey is completely voluntary and your responses will be confidential. Any information obtained during this study, which could identify you, will be kept strictly confidential. You may choose to exit the survey by closing the browser window at any time without harming your relationship with the researcher, the University of Louisville, or JCPS.

Please help her gather data to determine if our professional development positively impacted student achievement. She is asking you to complete one survey, which should take less than ten minutes to complete. You have until March $9^{\text {th }}$ to complete the survey. She is looking for responses from $5^{\text {th }}$ grade teachers during the 2014-2015 school year. This data will only serve to tie student achievement data to participation in math.com PD, no school data or teacher data will be shared. 
Thank you for your help in evaluating our math.com PD, please click on the survey link below:

https://docs.google.com/forms/d/1qIC4aj1_joaS0Q9TA0Hp-

UeWwyJSWm_TMEkHbkz07g4/viewform 


\section{Improving Student Achievement Through}

\section{Reform Style Professional Development}

The purpose of this study is to determine how teachers in a Southeastern school district assess their personal skill level of Common Core State Standards while focusing on academic results as a result of participating in Common Core focused Professional Development. Student achievement data, reported through norm-referenced test scores (NRTs), will be examined. This will determine if there is a relationship between PD participation and student achievement scores. The overarching question for this research project will be: Does reform style professional development positively promote students' mathematics achievement?

Your participation in this survey is completely voluntary and your responses will be confidential. Any information obtained during this study, which could identify you, will be kept strictly confidential. You may choose to exit the survey by closing the browser window at any time without harming your relationship with the researcher, the University of Louisville, or the school district.

1. I agree to participate.

2. Name

- Yes

3. What is your highest level of education?

- Bachelors Degree

- Masters Degree

- Rank I

- Doctoral Degree

- Post-doctoral Study

4. During the 2014-2015 (last) school year what was your primary teaching responsibility?

- All subjects

- We departmentalize and I teach Math

- We departmentalize and I teach Reading

- We departmentalize and I teach Social Studies

- We departmentalize and I teach Writing

- Other

5. Including this school year (2015-2016), how many total years have you been employed as a teacher?

6. Including this school year (2015-2016), how many years have you been at your current school?

7. School you were employed by for the 2015-2016 school year. 
8. Do you have a math certification?

- Yes

- No

9. Including this school year (2015-2016), how many years have you taught math?

10. Did you teach math during the 2015-2016 school year?

- Yes

- No

11. Did the duration of the Math's Department's Professional Development work for you? Providing four, six-hour days of PD during the course of the 2014-2015 school year, one for each Cycle.

- Yes

- No

12. How many Math.com sessions did you attend during the 2014-2015 school year?

- 0

- 1

- 2

- 3

- 4

13. Please Indicate how well prepared you currently feel to do each of the following in your math instruction.

\begin{tabular}{|l|c|c|c|c|c|}
\hline & $\begin{array}{c}\text { Not at all } \\
\text { prepared }\end{array}$ & $\begin{array}{c}\text { A little } \\
\text { prepared }\end{array}$ & $\begin{array}{c}\text { Somewhat } \\
\text { prepared }\end{array}$ & $\begin{array}{c}\text { Fairly well } \\
\text { prepared }\end{array}$ & $\begin{array}{c}\text { Very well } \\
\text { prepared }\end{array}$ \\
\hline $\begin{array}{l}\text { Take a } \\
\text { students' prior } \\
\text { understanding } \\
\text { into account } \\
\text { when planning } \\
\text { curriculum } \\
\text { and } \\
\text { instruction. }\end{array}$ & 1 & 2 & 3 & 4 & 5 \\
\hline $\begin{array}{l}\text { Develop } \\
\text { students' } \\
\text { conceptual } \\
\text { understanding } \\
\text { of } \\
\text { mathematics. }\end{array}$ & 1 & 2 & 3 & 4 & 5 \\
\hline $\begin{array}{l}\text { Make } \\
\text { connections } \\
\text { between } \\
\text { mathematics } \\
\text { and other } \\
\text { disciplines. }\end{array}$ & 1 & 2 & 3 & 4 & 5 \\
\hline $\begin{array}{l}\text { Lead a class } \\
\text { of students }\end{array}$ & 1 & 2 & 3 & 4 & 5 \\
\hline
\end{tabular}




\begin{tabular}{|l|l|l|l|l|l|}
\hline $\begin{array}{l}\text { using inquiry } \\
\text { strategies. }\end{array}$ & & & & \\
\hline $\begin{array}{l}\text { Routinely use } \\
\text { and evaluate } \\
\text { formative } \\
\text { assessment } \\
\text { lessons to } \\
\text { gauge their } \\
\text { understanding. }\end{array}$ & 1 & 2 & 3 & 4 & 5 \\
\hline $\begin{array}{l}\text { Manage a } \\
\text { class of } \\
\text { students } \\
\text { engaged in } \\
\text { hands- } \\
\text { on/project- } \\
\text { based work. }\end{array}$ & 1 & 2 & 3 & 4 & 5 \\
\hline
\end{tabular}

14. What, if anything, would you like to receive from professional development that you did not receive in the math.com PD?

* I would like to receive the results of this study via email: 


\section{CURRICULUM VITAE}

Amy Colucci

EDUCATION acolucci@gmail.com

@acolucci

(502) 299-3436

August 2013 - June 2016

Ed.D - Social Justice Program

University of Louisville, Louisville, KY

Rank I, Curriculum and Instruction Indiana Wesleyan University, Louisville, KY

Master of Education, Curriculum and Instruction Indiana Wesleyan University, Louisville, KY

Elementary Education, Bachelor of Science

Ball State University, Muncie, IN

\section{EXPERIENCE}

Engrade Engagement Manager

McGraw-Hill Education, Santa Monica, CA

- Project manager for school districts, providing project management, training, and support.

District Instructional Technology Resource Teacher

August 2007 - June 2015

Jefferson County Public Schools, Louisville, KY

- Provided district wide math, social media, walk throughs, assessment building, and instructional technology related professional development to teachers and administrators. Managed district accounts, including Google Apps for Education Domain, Edmodo, eChalk, SMART Technologies, and eWalk.

Part Time University Professor

University of Louisville, Louisville, KY

- Guide pre-service teachers through effective integration of technology into math instruction to facilitate student achievement in the K-12 classroom environment. 
Curriculum Developer

January 2004 - January 2007

Elementary eSchool, Jefferson County Public Schools, Louisville, KY

- Created interactive lessons correlated to the state adopted curriculum standards.

Professional Affiliations and Conference Presentations

Women in School Administration (WSA)

Public Relations and Communications Board Member - 2014-2016

Greater Louisville Council of Teachers of Mathematics (GLCTM)

Communications Board Member - 2010-2015

National Council of Teachers of Mathematics (NCTM)

Presentations in 2011, 2012, 2013, 2014

International Society for Technology in Education (ISTE)

Presentations in 2011, 2012

Kentucky Society for Technology in Education (KYSTE)

Presentations in 2008, 2009, 2010, 2011, 2012, 2013, 2014, 2015

Florida Educational Technology Conference (FETC)

Presented in 2010 